\title{
Perturbations to the Spatial and Temporal Characteristics of the Diurnally-Varying Atmospheric Boundary Layer Due to an Extensive Wind Farm
}

\author{
V. Sharma ${ }^{1} \cdot$ M. B. Parlange ${ }^{2} \cdot$ M. Calaf ${ }^{3}$
}

Received: 24 July 2015 / Accepted: 21 July 2016 / Published online: 4 August 2016

C Springer Science+Business Media Dordrecht 2016

\begin{abstract}
The effect of extensive terrestrial wind farms on the spatio-temporal structure of the diurnally-evolving atmospheric boundary layer is explored. High-resolution largeeddy simulations of a realistic diurnal cycle with an embedded wind farm are performed. Simulations are forced by a constant geostrophic velocity with time-varying surface boundary conditions derived from a selected period of the CASES-99 field campaign. Through analysis of the bulk statistics of the flow as a function of height and time, it is shown that extensive wind farms shift the inertial oscillations and the associated nocturnal low-level jet vertically upwards by approximately $200 \mathrm{~m}$; cause a three times stronger stratification between the surface and the rotor-disk region, and as a consequence, delay the formation and growth of the convective boundary layer (CBL) by approximately $2 \mathrm{~h}$. These perturbations are shown to have a direct impact on the potential power output of an extensive wind farm with the displacement of the low-level jet causing lower power output during the night as compared to the day. The low-power regime at night is shown to persist for almost $2 \mathrm{~h}$ beyond the morning transition due to the reduced growth of the CBL. It is shown that the wind farm induces a deeper entrainment region with greater entrainment fluxes. Finally, it is found that the diurnally-averaged effective roughness length for wind farms is much lower than the reference value computed theoretically for neutral conditions.
\end{abstract}

Keywords Terrestrial wind farms · Atmospheric boundary layer · Diurnal cycles · Wind-farm control · General circulation models

V. Sharma

varun.sharma@epfl.ch

1 School of Architecture, Civil and Environmental Engineering, EPFL, Lausanne, Switzerland

2 Department of Civil Engineering, University of British Columbia, Vancouver, Canada

3 Department of Mechanical Engineering, University of Utah, Salt Lake City, USA 


\section{Introduction}

The interaction of the turbulent atmospheric boundary layer (ABL) with an extremely large wind farm is studied by considering three distinct vertical regions of the flow. The bottom layer consists of the region between the surface and the bottom of the rotor-disk region and includes the surface layer of the standard ABL. The second layer is the rotor-disk region characterized by the presence of the wind-turbine wakes and thus this region is often referred to as the wake region. The third region consists of the flow above the top of the rotor-disk region extending up to the top of the ABL. Treating a wind farm as an enhanced surface roughness is perhaps the most common concept used to represent the atmospheric flow over turbines. Modelling of large-scale (in comparison to surface roughness) momentum-absorbing elements near the surface as enhanced surface roughness has counterparts in studies of flows over vegetated canopies and urban environments (Tseng et al. 2006; Giometto et al. 2016). Note that, in the above framework, the ABL is partitioned vertically, and is dependent on neglecting entrance effects and the formation of an internal boundary layer that would be prominent features in a flow over a realistic finite-sized wind farm.

The rotor-disk region consists of an extremely complex flow with turbulent wakes of wind turbines interacting with each other as well as the background atmospheric turbulence simultaneously. The defining features of the wakes depend upon the blade-geometry and operation of the individual wind turbines, the spatial arrangement of these wind turbines in a wind farm and the turbulence characteristics of the atmospheric flow, which depend ultimately on the surface roughness and thermal stratification. This region has received much attention due to the wind-energy industry's focus on maximizing power production as well as lowering operational and maintenance costs. It is now well understood that when several wind turbines are clustered together forming a wind farm, the net harvested power is less than what theoretically would be extracted by an equal number of isolated turbines (Barthelmie et al. 2010). Several works have analyzed the effects of wind-turbine arrangement and wake superposition on the resultant harvested power (Barthelmie et al. 2007, 2009; Barthelemie and Jensen 2010; Porté-Agel et al. 2013; Stevens et al. 2014) as well as wake interactions and the wake-recovery processes (Frandsen 1992; Emeis and Frandsen 1993; Frandsen et al. 2006; Cal et al. 2010; Markfort et al. 2012). Analytical wake models for wind farms developed decades ago (Lissaman 1979; Jensen 1983; Katic et al. 1986) continue to serve as the bedrock of various engineering software packages used for wind-farm design such as the Wind Atlas Analysis and Application Program (WAsP).

With the availability of datasets from offshore wind farms such as the Horns Rev and Nysted wind farms located in the North Sea, most research has involved the standard case of wind turbines within a neutrally stratified atmospheric flow, which is also the most frequent stratification encountered in the marine ABL. The growing interest in terrestrial wind farms has resulted in research extending to scenarios where wind turbines are immersed in either a stably stratified or convective boundary layer (CBL). Results illustrate the relevance of accounting for the atmospheric stratification, showing major differences in power output, wake recovery, and turbulence intensity within the wind farm. For example, Baker and Walker (1984) found that the wake deficit behind a 2.5-MW wind turbine decreased by $10 \%$ in a flow with higher turbulence levels, indicating that in the CBL, the wake recovers more rapidly. These results are consistent with Iungo and Porté-Agel (2014) who used wind-lidar measurements. Keck et al. (2014), who analyzed the effect of atmospheric stability on wake meandering and the power production of wind turbines, showed that wind-turbine wakes are up to $10 \%$ weaker under unstable conditions, and found wake-induced power losses 
of up to $12 \%$ higher in very stable scenarios when compared to the neutral stratification. Using a thermally-stratified wind tunnel, Zhang et al. (2013) observed a $15 \%$ weaker wake deficit at the wake centre in the CBL, and concluded that in the CBL there is an enhanced radial momentum transfer within the turbines' wakes that leads to a more rapid momentum recovery. As a result of this more rapid wake recovery, Churchfield et al. (2012) showed that for the case of a wind turbine placed behind another turbine, the power was between 15-20\% higher under convective stratification.

In contrast, in the case of a wind farm immersed in a stably stratified flow, results were found to have an opposite trend. For example, Abkar and Porté-Agel (2013) found that momentum entrainment is limited by the thermal inversion leading to a slower wake recovery and a lower power production. They measured a $35 \%$ power reduction when the potential temperature lapse rate of the free atmosphere was increased from 1 to $10 \mathrm{~K} \mathrm{~km}^{-1}$. Similarly, Barthelemie and Jensen (2010) estimated wind-farm efficiency reductions of up to $9 \%$ in stable conditions compared to the unstable scenario, for wind speeds of about $9 \mathrm{~m} \mathrm{~s}^{-1}$. Results from Magnusson and Smedman (1994) also supported the fact that wind-turbine wake deficits are larger in the case of a stably stratified atmospheric flow. In addition Hancock and Pascheke (2010) showed that in a moderately stable boundary layer (SBL), the wind-turbine wake height is reduced and the far-wake width is increased when compared to the neutral case.

Abkar and Porté-Agel (2015a) modelled a single wind turbine within three characteristic atmospheric stratifications showing how the turbulent kinetic energy (TKE) within the corresponding wakes is distributed, and with different intensities for different stabilities. Using a TKE budget analysis, they also showed how atmospheric stratification modifies the spatial distribution of the turbulence production, dissipation and transport terms within the wake. Their results confirmed a faster wake recovery in the convective regime due to an enhanced flow entrainment, with stronger wake meandering and a stronger axis asymmetry in the wake.

In comparison to the wake region, flow above and below the rotor-disk region has only recently been subjected to increasing scrutiny. One area of research is focused towards understanding the influence of terrestrial wind farms on microscale and mesoscale hydrometeorology. For example, Roy (2011) and Fitch et al. (2013b) using a large-scale numerical weather prediction model [such as the popular Weather Research and Forecasting (WRF) model] found that large wind farms modify the near-surface air temperature and humidity as well as the surface sensible and latent heat fluxes, resulting in lower air temperatures during daytime and warmer air at night. Similar trends were found in the field for existing large wind farms (Zhou et al. 2012; Xia et al. 2015). While the reported values of these changes were small, these observations generated considerable interest since most terrestrial wind farms are installed over existing farmland and such perturbations have the potential to affect crop dynamics (Calaf et al. 2014) and irrigation demand (Higgins et al. 2015). These simulations represented wind turbines as elevated momentum sinks and sources of TKE and contributions by Roy and Traiteur (2010), Fitch et al. (2012) and Abkar and Porté-Agel (2015b) have successively increased the fidelity of such wind-farm representation.

Another branch of research is aimed at computing the global wind-power potential and the possible effects of large-scale wind-farm deployment on climate dynamics. Studies such as Keith et al. (2004), Kirk-Davidoff and Keith (2008), Barrie and Kirk-Davidoff (2010) and Wang and Prinn (2010) used general circulation models (GCMs) and used the concept of enhanced surface roughness to model the effect of large wind farms (Frandsen 1992; Calaf et al. 2010; Meneveau 2012).

The principal feature of atmospheric flow in the presence of a wind farm is the perturbed vertical momentum-flux profile. This distinctive profile shows maximum shear stress at the 
top of the rotor disk, giving support to the enhanced surface roughness concept mentioned above. Beginning from the top of the rotor disk and moving towards the surface, the flow experiences a dramatic decrease in the stress, so much so that at the bottom of the rotor disk, the stress is in fact lower than the corresponding value in an unperturbed ABL at a similar height. This fact, coupled with the concept that dynamic stability of the ABL is governed largely by the thermal energy balance of the surface and turbulent mixing near the surface, implies that the presence of a wind farm can significantly alter the structure of the diurnally-varying ABL.

Quasi-steady flow scenarios for different stable (Lu and Porté-Agel 2011; Aitken et al. 2014; Abkar and Porté-Agel 2015a; Bhaganagar and Debnath 2015) and unstable conditions ( $\mathrm{Lu}$ and Porté-Agel 2015) for wind farms have been explored recently using large-eddy simulations (LES). However a diurnal cycle is by its nature, a continual process of formation, growth, quasi-stationarity and ultimately decay of the (unstable) CBL followed by a similar cycle for the SBL. Thus, not only the steady-state structure but the dynamical nature of the transient ABL can be potentially altered by wind farms. This is precisely what we set out to explore through our computational experiments of diurnal flow simulations in the presence of a wind farm. Two similar experiments have been performed by Fitch et al. (2013a), who used the WRF model to study the mesoscale influence of a finite-sized wind farm during the same diurnal cycle as used herein and by Abkar et al. (2016) who performed a high-resolution LES of a finite-sized wind farm to study the effects of an evolving ABL on the wakes of wind turbines. While these two studies have used different simulation methodologies and have different motivations as compared to the present study, they serve as important benchmarks to validate our results.

In Sect. 2, a concise description of the LES model used is provided along with a detailed description of the simulation set-up and the post-processing of the LES data (Sect. 2.1).

Validation of the diurnal cycle simulation without wind farms is performed using field data and previous simulations of the well-known CASES-99 dataset (Sect. 2.2). Section 3 discusses the perturbations to the spatio-temporal structure of the evolving ABL induced by the wind farm by comparing bulk statistics of simulations with and without wind farms. In Sect. 4 we perform a mean kinetic energy (MKE) budget of the rotor-disk region of the wind farm (Sect. 4.1) and further focus on the effect of wind farms on the formation and growth of the CBL (Sect. 4.2), and the low-level jet formed during the late stable period (Sect. 4.3). The final part of the analysis focuses on the concept of considering wind farms as surfaces with enhanced roughness and the potential pitfalls in such an approach for terrestrial wind farms (Sect. 4.4). The results are placed in the context of providing specific implications for wind-farm operators and for climatologists studying the effect of large-scale wind-energy deployment on climate dynamics (Sect. 5).

\section{Methodology and Validation}

\subsection{Description of Large-Eddy Simulations}

The atmospheric LES model used solves the non-dimensional, filtered, incompressible Navier-Stokes equations together with the continuity equation. To ensure conservation of mass and energy of the inertial terms, the rotational form of the filtered Navier-Stokes equations is used (Moeng 1984). Additionally, the advection-diffusion equation for the filtered potential temperature $(\tilde{\theta})$ is solved. The Bousinesq approximation is used to compute the buoyant forces in the Navier-Stokes equations by replacing relative density fluctuation $\left(\rho^{\prime} / \rho\right)$ 
with relative temperature fluctuations $\left(\theta^{\prime} / \theta\right)$. The subgrid-scale (SGS) fluxes for momentum and heat are modelled using the Lagrangian scale-dependent dynamic Smagorinsky model and its scalar counterpart (Bou-Zeid et al. 2005; Calaf et al. 2011). The flow is driven by an imposed geostrophic flow with active Coriolis effects. Since the simulations are done to reproduce an extremely high Reynolds-number atmospheric flow, the viscous and molecular diffusive effects are neglected.

The code follows the numerical discretization of Moeng (1984) and Albertson and Parlange (1999a, b), where a pseudo-spectral discretization is used. Fourier transforms are used for the horizontal directions and second-order finite differences are used in the vertical direction. Use of Fourier methods implies that the domain is periodic in the horizontal directions and no lateral boundary conditions are needed and hence the domain size tends to infinity in practice. The equations are numerically integrated in time using a second-order AdamsBashforth scheme, and the non-linear convective term is de-aliased with the $3 / 2$ rule (Canuto et al. 1988). The code is fully parallelized with Message Passing Interface (MPI), using the "Fastest Fourier Transform in the West" (FFTW) (Frigo and Johnson 2005) for the Fourier transforms. The pressure solver is adapted for the parallel runs based on the pipeline Thomas algorithm (Povitsky and Morris 2000).

At the upper boundary, a zero vertical velocity is imposed at the top of the numerical domain, together with a zero momentum flux for the momentum equations and a zero vertical gradient for the potential temperature. As bottom boundary conditions, a zero vertical velocity is imposed for the vertical component of the momentum equations, while an equivalent surface shear stress is imposed for the horizontal components. The shear stress is parametrized using Monin-Obukhov similarity theory (Monin and Obukhov 1954), suitably adapted for LES using a methodology developed by Bou-Zeid et al. (2005) and Hultmark et al. (2013). The atmospheric stability correction functions developed by Brutsaert (1992) are used with the scalar surface roughness length taken to be one tenth of the aerodynamic roughness length (Brutsaert et al. 1989). Since the stability correction functions were initially developed for flat homogeneous surfaces and the wind turbines alter the momentum and heat fluxes near the surface, results should be considered as a first-order approximation. A lack of new experimental data does not allow for a better approach at the current time.

The wind-turbine model is based on the actuator disk concept using a parametrization developed by Meyers and Meneveau (2010) that provides formulations for both the axial as well as tangential forces. The inclusion of tangential forces allows for improved modelling of the near-wake region as shown by Wu and Porté-Agel (2011). An additional improvement is the ability of the actuator disk to rotate around the vertical axis to reflect the yawing action of wind turbines. This is achieved by interpolating wind-turbine forces onto the LES grid points using inverse distance weighing. For complete details and mathematical formulations of the LES model and the wind-turbine model used, see Sharma et al. (2015).

\subsection{Simulations and Validation Using CASES-99 Dataset}

Two principal simulations were performed; (a) no wind turbines as the baseline study (designated as noWT) and (b) a full wind farm with 24 wind turbines arranged in four rows and six columns with spacing of $7 D$ and $5 D$ in the streamwise and cross-stream directions respectively (designated as WT24). An additional simulation, WT1, with a single wind turbine was also performed to illustrate the effect of loading on the SBL. All turbines have a hub-height $\left(z_{h}\right)$ of $100 \mathrm{~m}$ with a rotor diameter $(D)$ of $100 \mathrm{~m}$, and all simulations have horizontal domain lengths of $\pi \mathrm{km}$ with vertical extent of $3 \mathrm{~km}$. The computational grid consists of $128 \times 128 \times 384$ points resulting in a numerical discretization of $\Delta_{x}, \Delta_{y}=24.54 \mathrm{~m}$ in 
(a)

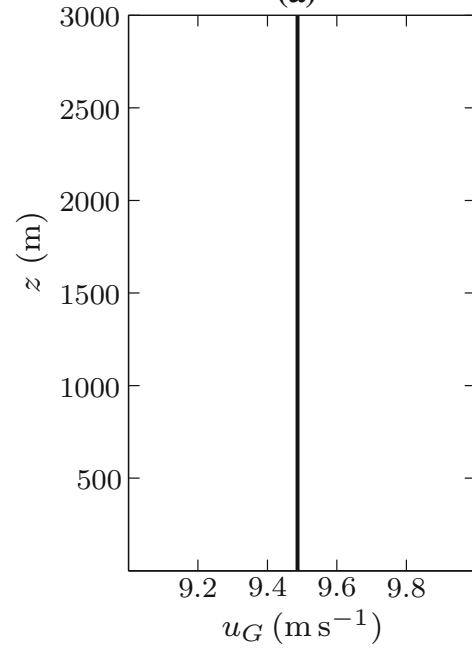

(b)

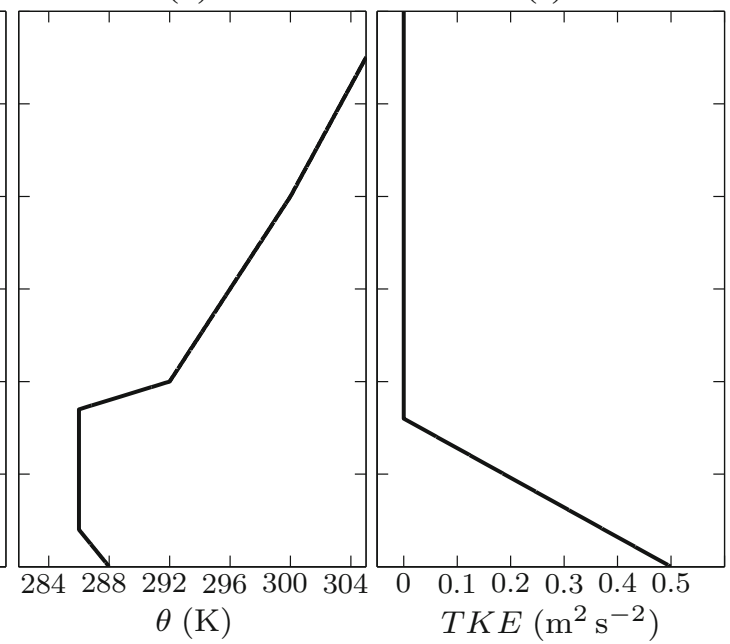

(d)

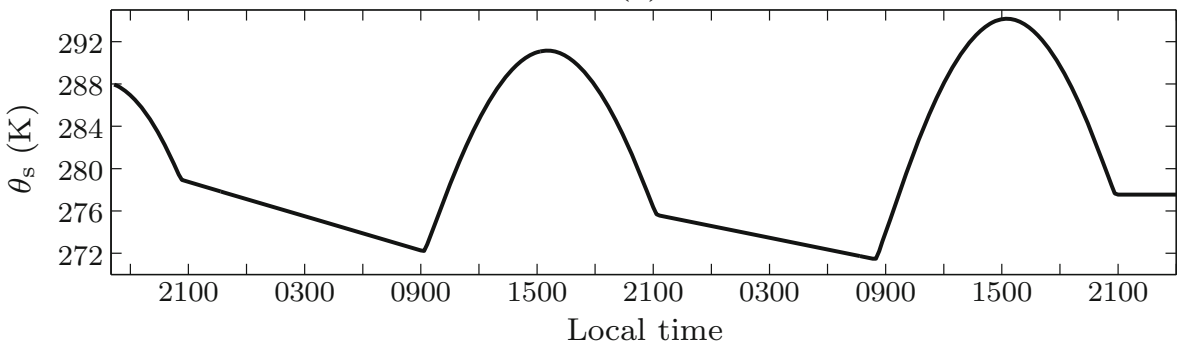

Fig. 1 Initial conditions for the diurnal cycle: $\mathbf{a}$ is the mean velocity, $\mathbf{b}$ the mean temperature profile, $\mathbf{c}$ TKE profile used for the random noise added on the mean velocity and temperature profiles, $\mathbf{d}$ temporal evolution of the imposed surface temperature

the horizontal and $\Delta_{z}=7.81 \mathrm{~m}$ in the vertical direction. An integration timestep of $0.2 \mathrm{~s}$ is used.

The Cooperative Atmosphere-Surface Exchange Study, CASES-99 (Poulos et al. 2002) dataset is used in this study. For simulation-based studies, a 58-h period beginning at $1400 \mathrm{~h}$ on 22 October 1999, for which the synoptic influenes were found negligible, has proven to be especially useful. This period has been simulated using LES (Kumar et al. 2010), single column models (Svensson et al. 2011) and regional scale models (Shin and Hong 2011). A mesoscale study of flow within and above a hypothetical wind farm during the same period was also recently performed by Fitch et al. (2013a). Here, a similar study using a comparatively higher resolution LES with an advanced SGS model is performed.

The simulations are forced using geostrophic wind components of $u_{G}=9.5 \mathrm{~m} \mathrm{~s}^{-1}$ and $v_{G}=0$ throughout the entire height of the domain as shown in Fig. 1a; this also serves as the initial velocity condition. The initial condition for temperature is shown in Fig. $1 \mathrm{~b}$. Atmospheric LES need to be initialized with a turbulent flow field to reflect atmospheric turbulence, and is usually achieved by adding suitable fluctuations to the initial mean velocity and temperature profiles. In the present study, this noise is computed using the TKE profile 
shown in Fig. 1c. The diurnal cycle is simulated using the time-evolving surface temperature shown in Fig. 1d. Complete details, including the functional forms of these profiles can be found in Kumar et al. (2010).

The simulation fields are processed by first computing (block) time averages of the flow quantities $\alpha, \beta \in\{u, v, w, \theta\}$ (represented by the overbar) for each point of the grid, followed by spatial averaging along the two horizontal directions (represented by \langle\rangle ). The correlation terms arising from these averaging operations are the traditional Reynolds flux terms as well as the dispersive stress terms; these quantities are also horizontally-averaged resulting in $\left\langle\overline{\alpha^{\prime} \beta^{\prime}}\right\rangle$ and $\left\langle\bar{\alpha}^{\prime \prime} \bar{\beta}^{\prime \prime}\right\rangle$ respectively. In addition to $\langle\bar{u}\rangle,\langle\bar{v}\rangle,\langle\bar{w}\rangle$ and $\langle\bar{\theta}\rangle$, we list below the principle terms of interest in our analysis,

$$
\begin{aligned}
& |\mathbf{u}|=\left\langle\sqrt{\bar{u}^{2}+\bar{v}^{2}+\bar{w}^{2}}\right\rangle, \\
& M K E=0.5\left[\langle\bar{u}\rangle^{2}+\langle\bar{v}\rangle^{2}+\langle\bar{w}\rangle^{2}\right], \\
& \left.T K E=0.5\left[\overline{\left\langle u^{\prime} u^{\prime}\right.}\right\rangle+\left\langle\overline{v^{\prime} v^{\prime}}\right\rangle+\left\langle\overline{w^{\prime} w^{\prime}}\right\rangle\right], \\
& \tau_{x}=\left\langle\overline{u^{\prime} w^{\prime}}\right\rangle+\left\langle\bar{u}^{\prime \prime} \bar{w}^{\prime \prime}\right\rangle+\tau_{1,3}^{s g s}, \\
& \tau_{y}=\left\langle\overline{v^{\prime} w^{\prime}}\right\rangle+\left\langle\bar{v}^{\prime \prime} \bar{w}^{\prime \prime}\right\rangle+\tau_{2,3}^{s g s}, \\
& \tau=\sqrt{\tau_{x}^{2}+\tau_{y}^{2}}, \\
& H_{s}=\left\langle\overline{w^{\prime} \theta^{\prime}}\right\rangle+\left\langle\bar{w}^{\prime \prime} \bar{\theta}^{\prime \prime}\right\rangle+\tau^{\text {sgs,scalar }} .
\end{aligned}
$$

It is thus evident that our analysis is focused on bulk flow statistics that vary only with height $(z)$ and time $(t)$. The time averaging is performed for a period of $10 \mathrm{~min}$; the averaging time needs to be judiciously chosen such that small-scale turbulent fluctuations have been averaged while the larger diurnal trends are maintained. The inclusion of dispersive stresses and the use of bulk quantities justifies the use of a short averaging time of $10 \mathrm{~min}$. On the other hand, this averaging time allows for the analysis of the transition events.

The simulation results are first validated using results from Kumar et al. (2010) and experimental data from the CASES-99 dataset. Results of the noWT simulation are principally used for validation, while the WT24 and WT1 simulation results are shown for reference and comparison. The first subplot in Fig. 2 shows the velocity magnitude at $10 \mathrm{~m}$ above the surface $\left(u_{10}\right)$. The noWT simulation $u_{10}$ time series agrees well with the CASES-99 data as well as the results of Kumar et al. (2010). In fact, in the convective regime, the noWT simulation results are closer to the experimental dataset than those of Kumar et al. (2010). This could be a result of the improved scalar SGS model employed herein. Note that the observed values are point measurements having a more oscillatory signal compared to the simulated results, which are spatially averaged. The second subplot shows the inter-comparison of the surface sensible heat flux $\left(H_{s, \text { surface }}=H_{s}\left(z=\Delta_{z} / 2, t\right)\right)$ and the third subplot shows the intercomparison for the surface friction velocity $\left(u_{\star}=\sqrt{\tau\left(z=\Delta_{z} / 2, t\right)}\right)$. In general, the noWT simulation results are broadly in agreement with the field dataset and the results of Kumar et al. (2010), having the same general trends with similar values. The four vertical dotted lines indicate the stability transition points $t_{s 1}=1010 \mathrm{~h}$ on Day $2(\mathrm{~S} \rightarrow \mathrm{U}), t_{s 2}=1810$ $\mathrm{h}$ on Day $2(\mathrm{U} \rightarrow \mathrm{S}), t_{s}=0940 \mathrm{~h}$ on Day $3(\mathrm{~S} \rightarrow \mathrm{U})$ and $t_{s 4}=1800 \mathrm{~h}$ on Day $3(\mathrm{U} \rightarrow \mathrm{S})$, where $(S \rightarrow U$ ) indicates a transition from stable to unstable (or convective) stratification and $(\mathrm{U} \rightarrow \mathrm{S})$ the other way around. These transitions are also referred to as morning and evening transitions respectively. During the course of the simulation, the maximum absolute Obukhov length $(L)$ was found to be approximately $40 \mathrm{~m}$ (apart from the transition periods, where $L$ is undefined). 

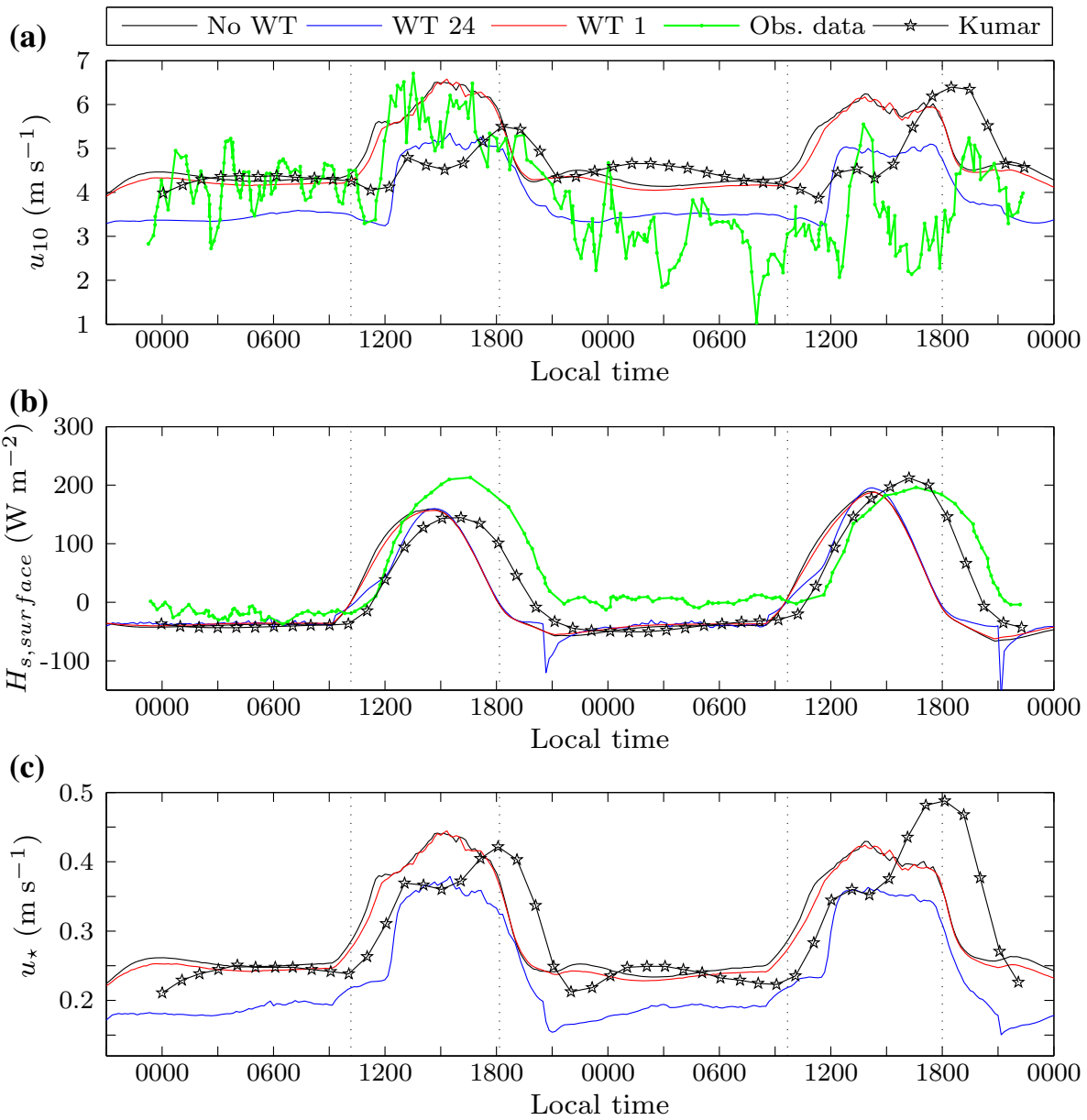

Fig. 2 Validation of the numerical simulations with the CASES-99 experimental data (green line) and the numerical results of Kumar et al. (2010) (stars). The black line represents the case without wind turbines, which is used for validation. The blue and red lines that represent the WT24 and WT1 simulations respectively are illustrated for reference; $\mathbf{a} 10-\mathrm{m}$ mean wind speed $\left(\mathrm{m} \mathrm{s}^{-1}\right)$, b surface sensible heat flux $\left(\mathrm{W} \mathrm{m}^{-2}\right)$, $\mathbf{c}$ friction velocity $\left(\mathrm{m} \mathrm{s}^{-1}\right)$

\section{Evolution of the Diurnally-Varying ABL}

In the previous section we described our methodology for the simulations and the analysis framework for post-processing the simulation data. We proceeded by validating our baseline simulation without the wind farm (noWT) with results from the existing literature. Here, we present the bulk statistics computed by these simulations. We begin with an illustration of mean velocity at hub-height for the WT24 and the WT1 simulations for a characteristic daytime (unstable) and a characteristic nighttime (stable) stratification shown in Fig. 3. Figure 3a,c illustrates the daytime (at $1100 \mathrm{~h}$ on Day 2) convective flow for the wind farm and the single wind-turbine cases, and Fig. 3b,d illustrates the nighttime (at $0300 \mathrm{~h}$ on Day 2) stable flow. A qualitative assessment of the WT24 simulation shows that during the convective period, wind turbines have a larger variance in orientation with shorter and broader wakes 
(a)

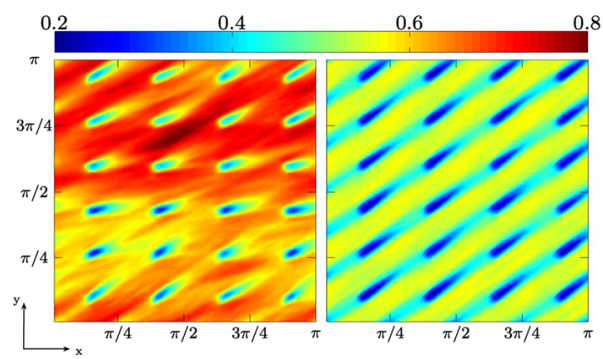

(c)

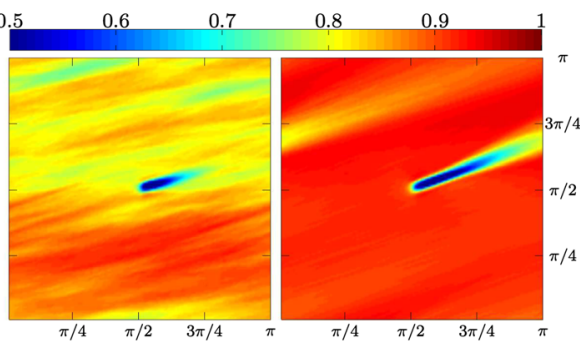

Fig. 3 Horizontal slices of the 10-min averaged, normalized velocity magnitude fields at hub-height for two characteristic periods of the WT24 and WT1 simulations: a WT24 daytime, b WT24 nighttime, c WT1 daytime, d WT1 nighttime

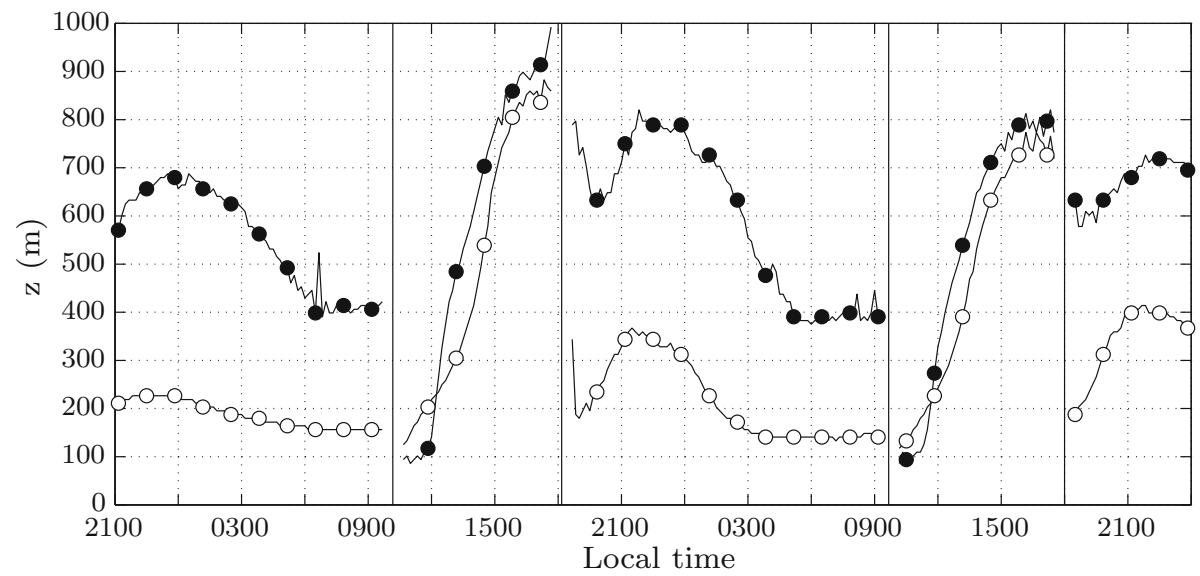

Fig. 4 Temporal evolution of the height of the ABL. The open markers represent the noWT simulation and the closed markers represent the WT24 simulation. Note that the ABL height is computed every 10 min based on bulk statistics. The four vertical lines mark the transition points at 1010 and $1810 \mathrm{~h}$ on Day 2 and 0940 and 1800 h on Day 3

(see Fig. 3a). On the other hand, in the stable period, the velocity at hub-height is smaller and unidirectional with wakes being longer and narrower, resulting in a greater interaction with the downstream turbines (Fig. 3b). For the single wind-turbine case a similar differential behaviour between the convective and stable periods is observed except for the fact that in this case, velocities at hub-height are greater at nighttime (Fig. 3c). The fact that the windturbine model can dynamically correct its yaw finds greater utility in unstable conditions with a rapid spatio-temporally varying flow direction. As each wind turbine corrects its yaw independent of the other turbines, this model permits us to simulate a more realistic wind farm with different orientations of each of the constituent wind turbines.

In Fig. 4, the height of the ABL during the course of the diurnal cycle is shown, where this is identified differently, according to the prevailing stratification. For unstable conditions the peak of the negative sensible heat flux in the entrainment region is used to identify the height of the ABL (or CBL during this period) (e.g. Mahrt and Lenschow 1976). For the stable period, we identify the top of the SBL as the height at which the vertical momentum flux falls to 10 percent of the surface value in the noWT simulation and the value at top of the rotor 
disk in the WT24 simulation. Our justification is that in the SBL, turbulence is generated mechanically and the sensible heat flux simply reflects the profiles of the vertical momentum flux, sensible heat flux and vertical momentum flux being linked through the TKE budget equation. In the SBL, sensible heat flux acts to destroy turbulence and is balanced by the shear divergence. In the standard flat-terrain SBL, the shear generation is maximum at the surface whereas in the presence of the wind farm, this occurs at the top of the rotor disk. Derbyshire (1990) derived an analytical expression for determining the height of the nocturnal SBL,

$$
h^{2}=\sqrt{3} k R_{f} \frac{u_{\star} L}{\left|f_{c}\right|},
$$

where $k$ is the von Karman constant, $R_{f}$ is the flux Richardson number and $\left|f_{c}\right|$ is the Coriolis parameter. Using these values from the LES data for a period between 0600 and $0900 \mathrm{~h}$ on Day 2 gives a height of $158 \mathrm{~m}$. This compares well with the height of SBL as $157 \mathrm{~m}$ for the same period presented in Fig. 4 and computed using the methodology adopted herein. The open symbols in Fig. 4 represent the noWT simulation and the closed symbols mark the WT24 counterpart. Note that the markers are present only to distinguish the two line plots showing the ABL height computed every $10 \mathrm{~min}$ based on the 10 -min averaged statistics. The four vertical lines represent the transition points during the simulation described earlier. It is found that the height of the ABL is $175 \%$ larger in the WT24 simulation as compared to the noWT simulation during the stable period. On the other hand, the steady-state convective period shows a mere $5 \%$ increase due to the presence of the wind farm. However, as will be shown in the next section, during the unstable regime, it is the dynamics of the formation and growth of the CBL that are significantly perturbed by the presence of a large wind farm.

Figures 5 and 6 show the diurnal evolution of ABL for the noWT and the WT24 simulations respectively through subplots showcasing the bulk quantities of (a) magnitude of velocity $(|\mathbf{u}|)$, (b) temperature $(\theta)$, (c) TKE, (d) vertical momentum flux $(\tau)$, and (e) sensible heat flux $\left(H_{s}\right)$. These quantities are normalized using the geostrophic velocity and surface temperature; the corresponding ABL heights from Fig. 4 are superimposed onto each subplot for reference. All figures contain four vertical lines to mark the transition points, and additionally a horizontal dotted line at hub-height is also marked for reference. The colours of these additional annotations are varied for improved visualization.

We limit our discussion to the period between the transition point at $1010 \mathrm{~h}$ on Day 2 and the transition point at $0940 \mathrm{~h}$ on Day 3, thus nearly covering an entire diurnal cycle. In the noWT simulation (Fig. 5), upon transition, the CBL is formed and begins to grow; this can be seen in the $H_{S}$ subplot with a growing region of positive heat flux capped by an entrainment zone with negative heat flux. The buoyant thermal plumes generated at the surface act as contributors in the TKE budget and the excess turbulent energy is dissipated through increased Reynolds stresses. Thus, values of $\tau$ and TKE reflect the trend in $H_{s}$. The wind speeds during the unstable period are marked by being sub-geostrophic and generally lower than at nighttime; this is due to the higher $\tau$ values in the CBL, and the dissipation of MKE. It is interesting to note that the computed height of the CBL neatly encompasses this low-velocity region. The partitioning of the total energy is therefore altered with higher TKE and lower MKE in the CBL as compared to the SBL. The growth of the CBL is ultimately constrained by the overlying capping inversion between the ABL and the free atmosphere and reaches a steady height at $1600 \mathrm{~h}, 2 \mathrm{~h}$ before the impending transition to the SBL. The SBL is marked by a sudden decrease in shear stress and TKE throughout the depth of the erstwhile CBL. The cooling surface results in negative $H_{S}$ at the surface. Turbulence is generated by mechanical shear at the surface and it can be seen that their corresponding values are negligible throughout the $\mathrm{ABL}$ apart from a shallow region near the surface. It is 


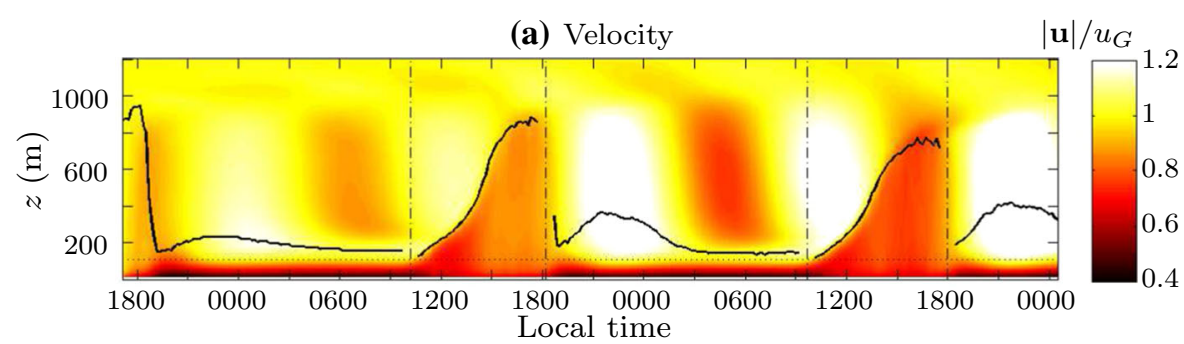

(b) Temperature

$\theta / \theta_{s}$

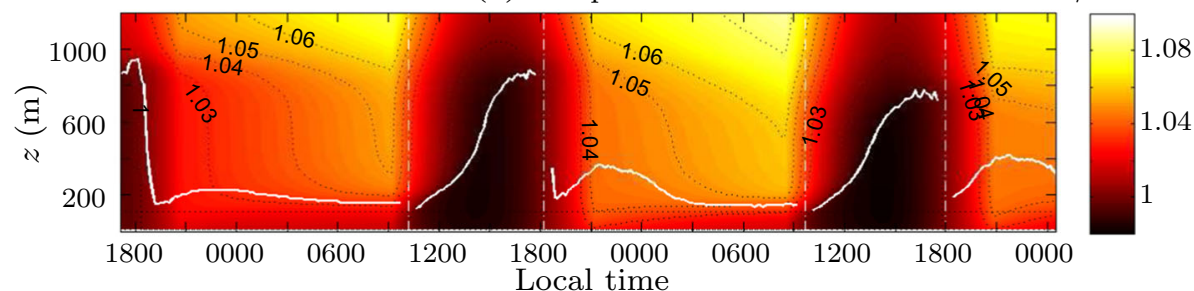

(c) TKE

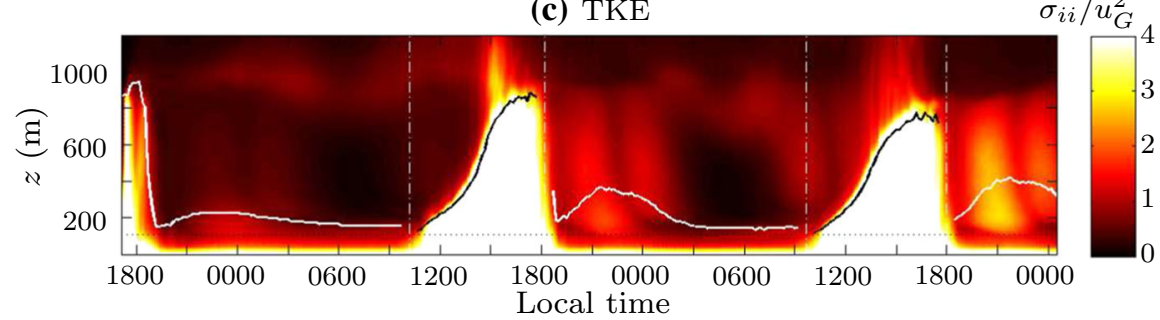

(d) Momentum Flux

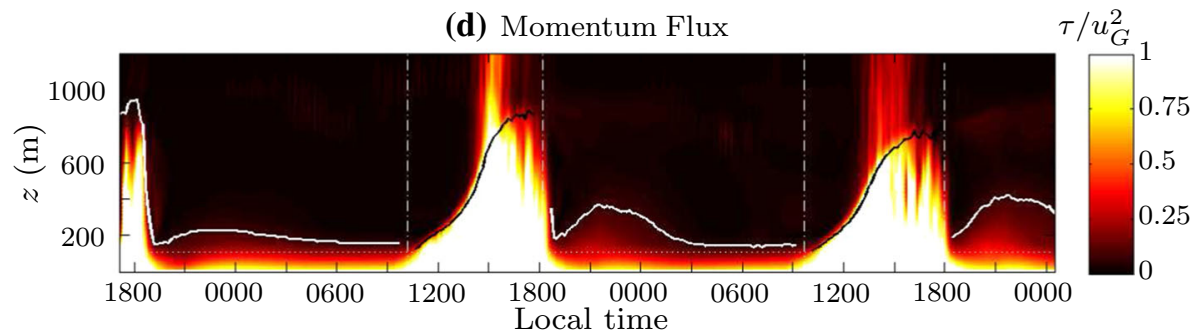

(e) Heat Flux

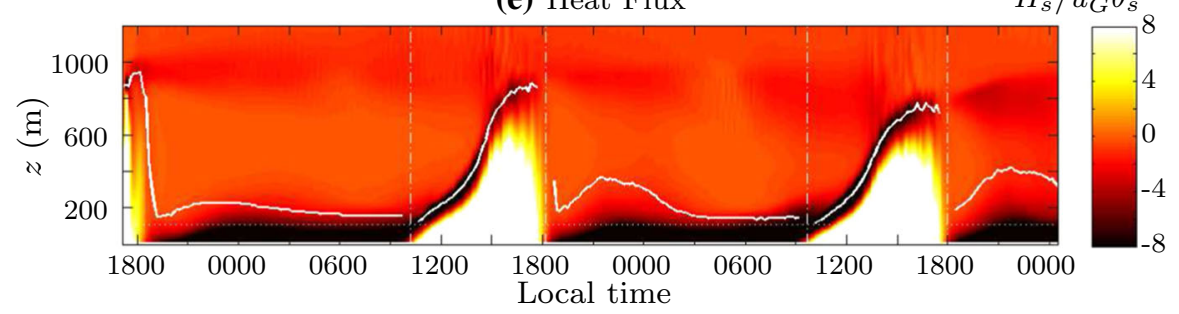

Fig. 5 noWT simulation: temporal evolution of the 10-min averaged vertical profiles of a velocity magnitude, b temperature, $\mathbf{c}$ TKE $\left(\times 10^{3}\right)$, $\mathbf{d}$ net vertical momentum flux $\left(\times 10^{3}\right)$ and e sensible heat flux $\left(\times 10^{5}\right)$. Geostrophic velocity and surface temperature are used as normalization scales. The four vertical lines mark the transition points at 1010 and $1810 \mathrm{~h}$ on Day 2 and 0940 and $1800 \mathrm{~h}$ on Day 3. The horizontal line at 100-m height represents the wind turbine hub-height. The height of the ABL shown in Fig. 4 is superimposed for reference 


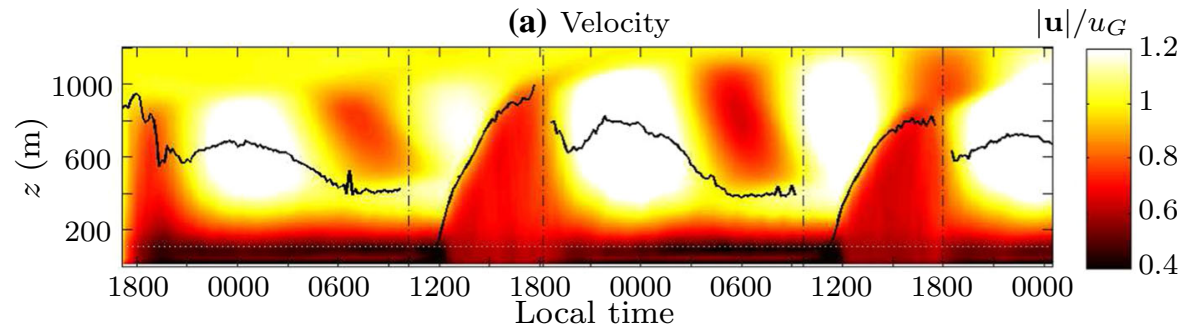

(b) Temperature

$\theta / \theta_{s}$

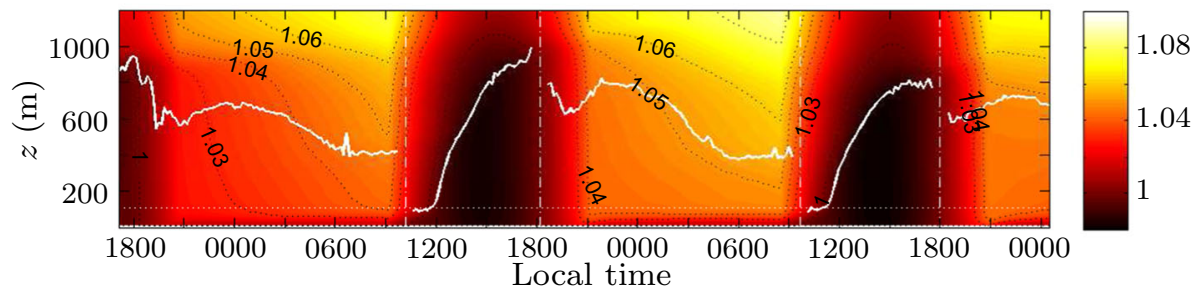

(c) $\mathrm{TKE}$

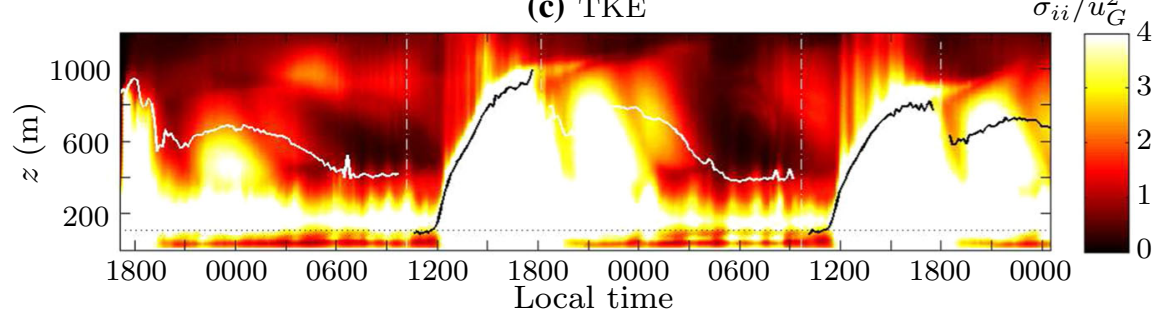

(d) Momentum Flux

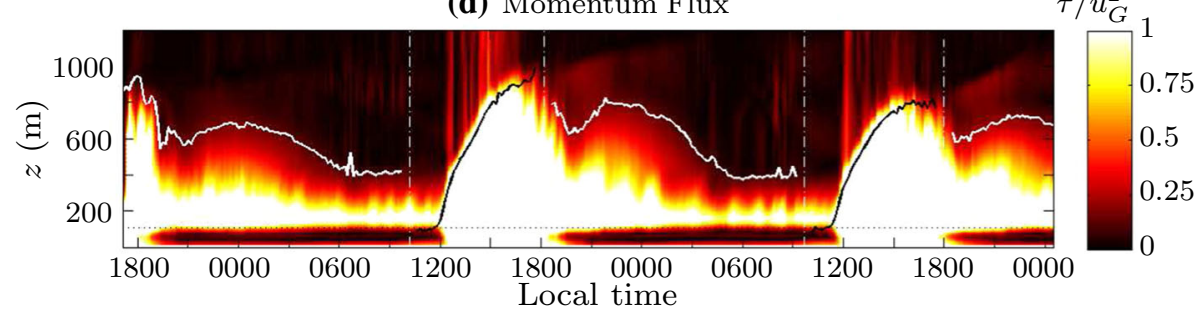

(e) Heat Flux

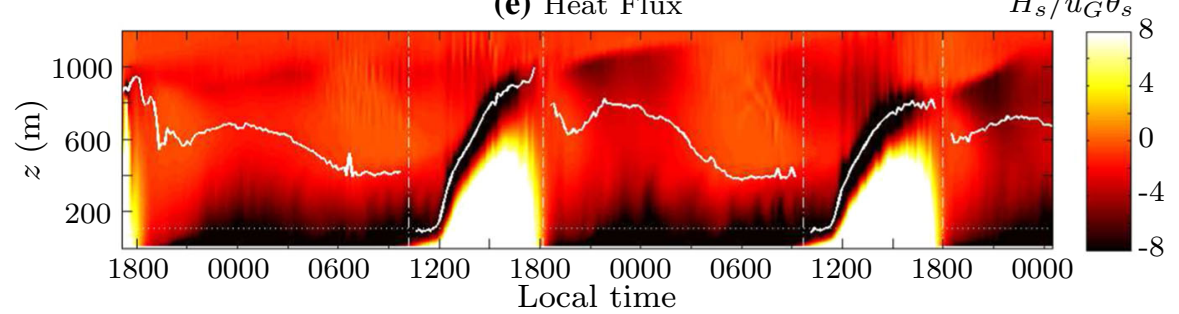

Fig. 6 WT24 simulation: temporal evolution of the 10-min averaged vertical profiles of a velocity magnitude, b temperature, $\mathbf{c}$ TKE $\left(\times 10^{3}\right)$, $\mathbf{d}$ net vertical momentum flux $\left(\times 10^{3}\right)$ and e sensible heat flux $\left(\times 10^{5}\right)$. Geostrophic velocity and surface temperature are used as normalization scales. The four vertical lines mark the transition points at 1010 and $1810 \mathrm{~h}$ on Day 2 and 0940 and $1800 \mathrm{~h}$ on Day 3. The horizontal line at 100-m height represents the wind turbine hub-height. The height of the ABL shown in Fig. 4 is superimposed for reference 
worthwhile to note that the methodology used to identify the height of the SBL delineates the height below which the cooling from the surface extends quite clearly. The flow field above $100 \mathrm{~m}$ accelerates to super-geostrophic velocities just after $2100 \mathrm{~h}$, and this high velocity region ultimately shrinks to a confined space just above $100 \mathrm{~m}$ beginning around $0300 \mathrm{~h}$ until $1000 \mathrm{~h}$. This region is otherwise known as the low-level jet (LLJ), which collapses upon transition to the convective regime. The dynamics of the flow above the SBL are governed by a balance of geostrophic and Coriolis forces in the absence of any friction. This is the well-known inertial oscillation phenomenon that has been observed in various flat-terrain field campaigns (Blackadar 1957; Stensrud 1996; Banta et al. 2002).

Before proceeding further, it is pertinent to place these results in the context of the existing literature on the subject of the diurnal cycle over flat terrain under clear-sky conditions. The results of the noWT simulation show many notable features such as the initial linear growth of the CBL followed by a convex (faster) growth while being capped by an entrainment region (Wyngaard and Coté 1974; Mahrt and Lenschow 1976; Sun and Ogura 1980), the rapid decay of shear stress and TKE throughout the depth of the ABL following the evening transition (Nieuwstadt and Brost 1986; Sorbjan 1997) and the inertial oscillations observed above the SBL giving rise to the LLJ in the late stable period (Blackadar 1957). In general the noWT simulation also shows consistency with LES results presented in Basu et al. (2008) and Kumar et al. (2010).

Figure 6 shows the spatio-temporal evolution of the ABL in the presence of a wind farm and the large-scale perturbations induced in relation to the noWT simulation in Fig. 5. Once again focusing on the period between $1010 \mathrm{~h}$ on Day 2 and the transition point at $0940 \mathrm{~h}$ on Day 3, it is immediately apparent that the formation and growth of the CBL is significantly different from the noWT simulation. The sensible heat flux has a slow increase until $1200 \mathrm{~h}$, at which time there is a sudden increase in the growth of the CBL. It can also be seen that the momentum flux and TKE are much lower between the surface and hub-height than above effectively decoupling the mixing between the surface and the air aloft. At $1200 \mathrm{~h}$, the sudden growth of the CBL occurs as the flux values as well as the TKE below the rotor disk increase sharply. The growth of the CBL itself follows a concave trend (decreasing rate of growth) as opposed to the convex shape of CBL growth (increasing rate of growth) in the noWT simulation. Velocities are sub-geostrophic, similar to the noWT simulation and encapsulated well by the computed height of the CBL. Upon transition to the SBL, the general trend in the velocity is similar to the noWT simulation with the main difference being that the LLJ is shifted upwards by the wind farm. The LLJ in the presence of the wind farm is observed to form above the rotor-disk region, with a more extensive vertical extent as compared to the noWT simulation. The differences between the WT24 and the noWT simulations are far more evident for the momentum flux and the TKE. It can be observed that a layer of high shear stress and TKE persists above the rotor-disk region throughout the SBL, reaching a constant thickness between 0600 and $1000 \mathrm{~h}$. In contrast, the momentum flux and TKE values below the rotor disk are reduced to negligible values rapidly upon transition and remain as such throughout the stable period. Thus the main source of turbulence in the presence of the wind farm during the stable period is at the top of the rotor disk with much weaker turbulence beneath the rotor disk. It is further interesting to note that due to the additional mixing induced by wind-turbine wakes, the negative heat-flux region extends deeper into the ABL and it is more diffused with significant oscillations in its vertical extent as compared to the noWT simulation.

The results of the WT24 simulation are similar to the SBL simulations of Lu and PortéAgel (2011) with a decrease in turbulence levels below the rotor-disk region and the upward shift of the LLJ, as also reported in LES of finite-sized wind farms (Abkar et al. 2016) 


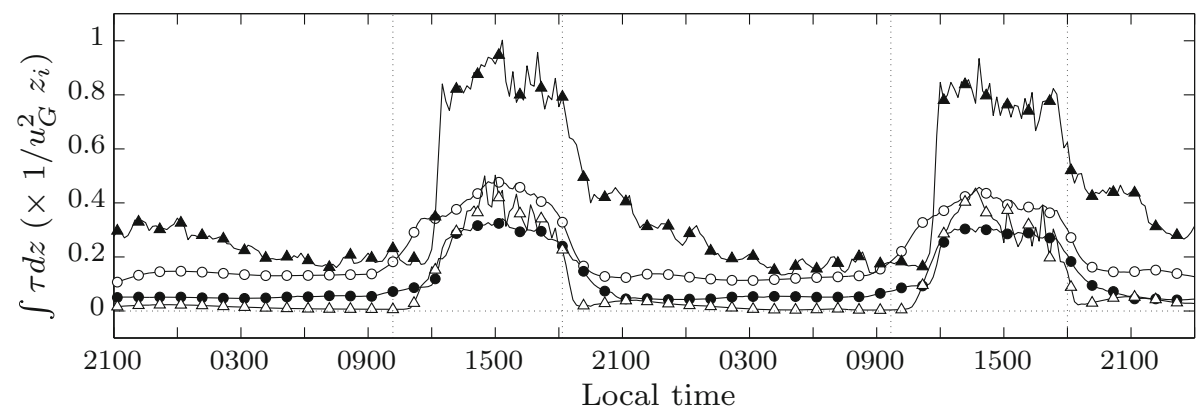

Fig. 7 Momentum flux integrated between $z=\Delta_{z} / 2$ and $z_{h}-D / 2$ (marked as circles) and between $z=z_{h}+D / 2$ and $2 z_{h}$ (marked as triangles). The noWT and WT24 simulations are represented by open and closed markers respectively. The four vertical lines mark the transition points at 1010 and $1810 \mathrm{~h}$ on Day 2 and 0940 and $1800 \mathrm{~h}$ on Day 3. Values are scaled by the geostrophic velocity and a reference boundary-layer height of $1000 \mathrm{~m}$

and WRF model simulations (Fitch et al. 2013a). The results for the quasi-steady CBL (for example, between 1500 and 1800 h on Day 2), compare well with the trends shown by Lu and Porté-Agel (2015), namely, the slight increase in the height of the late CBL and a deeper entrainment region with relatively higher heat flux as compared to the noWT simulation.

Figure 7 focuses on the perturbation of the momentum-flux profiles due to a large wind farm in the regions above and below the rotor-disk region in comparison to the noWT simulation. The momentum flux $(\tau)$ is integrated vertically between $z=\Delta_{z} / 2$ and $z_{h}-D / 2$ (marked as circles and referred to as $\mathcal{L}$ ) and between $z=z_{h}+D / 2$ and $2 z_{h}$ (marked as triangles and referred to as $\mathcal{H}$ ). The noWT and WT24 simulations are represented by open and closed markers respectively, with transitions points marked by vertical dotted lines.

For the noWT simulation, $\mathcal{H}$ is smaller than $\mathcal{L}$ for the entire diurnal cycle $(0.03 \leq$ $\left.\mathcal{H}_{\text {noWT }} / \mathcal{L}_{\text {noWT }} \leq 0.9\right)$ as expected. The upper limit of the $\mathcal{H} / \mathcal{L}$ ratio is found only during the late convective period (between 1500 and $1800 \mathrm{~h}$ ); in contrast, for the WT24 simulation, $\mathcal{H}$ is larger than $\mathcal{L}$ throughout the diurnal cycle $\left(1.1 \leq \mathcal{H}_{\text {WT24 }} / \mathcal{L}_{\text {WT24 }} \leq 9\right)$. The upper limit of the ratio $(\mathcal{H} / \mathcal{L} \approx 9)$ is found in the early stable period around $2100 \mathrm{~h}$, and is due to the rapid decay of the near-surface stresses after the evening transition in combination with the slow decay of stresses above the rotor-disk region (see Fig. 6d). Interestingly, for both the steady-state SBL (between 0400 and $0900 \mathrm{~h}$ ) and the late CBL (between 1500 and $1800 \mathrm{~h}$ ), $\mathcal{H}_{\mathrm{WT} 24} / \mathcal{L}_{\mathrm{WT} 24}=3$.

Perturbation of the near-surface stresses due to the wind farm is found to be significant with a reduction of $60 \%$ throughout the diurnal cycle. Near-surface mixing is the only mechanism available for propagating cooling from the surface upwards $\left(\mathcal{L}_{\mathrm{WT} 24} / \mathcal{L}_{\text {noWT }} \approx 0.4\right)$. As we shall see in the following section, the perturbation induced by wind farms has a significant impact on, (a) structure of the SBL, and (b) formation and growth of the CBL (Sect. 4.2).

\section{Analysis}

\subsection{Mean Kinetic Energy Budget}

The MKE budget terms (MKE is defined in Sect. 2.1) were computed for the period beginning at $2300 \mathrm{~h}$ on Day 1 and continued until $1900 \mathrm{~h}$ on the following day. The budget equation for MKE is as follows, 


$$
\begin{aligned}
\frac{\partial(M K E)}{\partial t}=f_{c}\langle\bar{v}\rangle u_{G} & +\underbrace{\left\langle\overline{f_{x}^{w t}}\right\rangle\langle\bar{u}\rangle+\left\langle\overline{f_{y}^{w t}}\right\rangle\langle\bar{v}\rangle+\left\langle\overline{f_{z}^{w t}}\right\rangle\langle\bar{w}\rangle}_{\mathrm{I}} \\
& \underbrace{-\left(\langle\bar{u}\rangle \frac{\partial\left\langle\overline{u^{\prime} w^{\prime}}\right\rangle}{\partial z}+\langle\bar{v}\rangle \frac{\partial\left\langle\overline{v^{\prime} w^{\prime}}\right\rangle}{\partial z}\right)}_{\mathrm{II}} \\
& \underbrace{-\left(\langle\bar{u}\rangle \frac{\partial\left\langle\bar{u}^{\prime \prime} \bar{w}^{\prime \prime}\right\rangle}{\partial z}+\langle\bar{v}\rangle \frac{\partial\left\langle\bar{v}^{\prime \prime} \bar{w}^{\prime \prime}\right\rangle}{\partial z}\right)},
\end{aligned}
$$

where terms represent the loss of the MKE due to wind-turbine forces (term I), the contribution of MKE due to Reynolds fluxes (term II), dispersive stresses (term III), the geostrophic forcing of the simulation (term IV) and finally, the acceleration term or the residual of the balance of forces (term V). The buoyancy force is neglected since $\langle\bar{w}\rangle=0$. As this analysis was performed to understand the balance of forces within the wake region of the wind farm in the bulk sense, Eq. 3 was integrated between $z_{h}-D / 2$ and $z_{h}+D / 2$. Note that, in comparison to the standard MKE budget equation (see, for example, Finnigan 2000) terms due to advection, SGS dissipation and pressure perturbation were found to be negligible upon vertical integration and are not shown. Furthermore the turbulent quantities are not reformulated into transport and dissipation terms since the transport term in general is the dominant term (Calaf et al. 2010). The budget terms are normalized and shown in Fig. 8, where the two vertical lines represent the transition points at 1010 and $1810 \mathrm{~h}$. While Calaf et al. (2010) showed that the vertical momentum flux plays the dominant role in replenishment of MKE in the rotor-disk region, it can be seen that this is valid only for unstable conditions where term II is indeed found to be dominant (it is $70 \%$ of term I). On the other hand, during

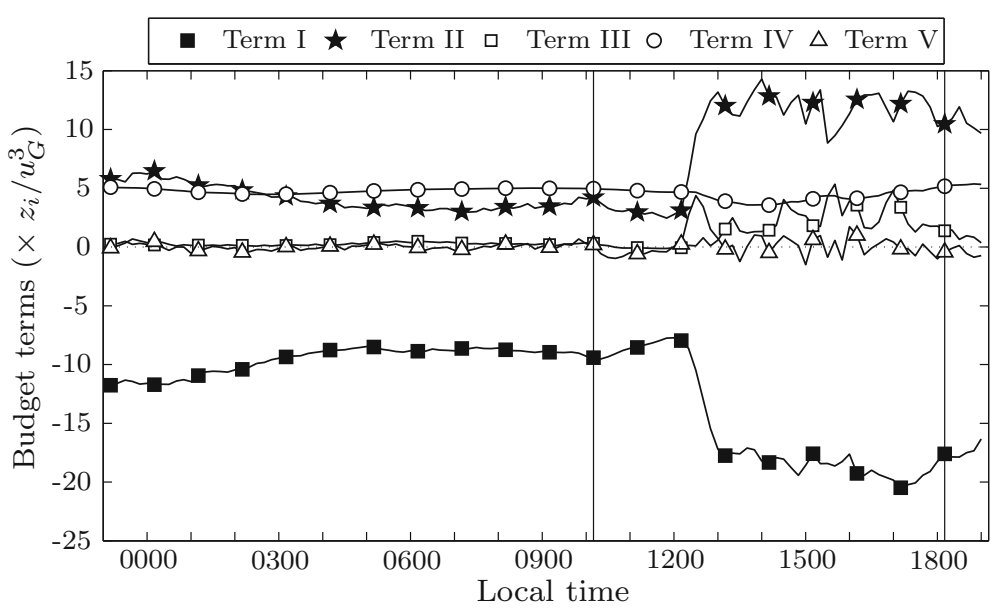

Fig. 8 MKE budget during a diurnal cycle: term I: loss of the MKE due to wind-turbine forces, term II: contribution of MKE due to Reynolds fluxes, term III: dispersive stresses and term IV: geostrophic forcing of the simulation. Term V shows the acceleration term or the residual. All values are scaled using a reference boundary-layer height of $1000 \mathrm{~m}$ and the geostrophic velocity. The two vertical lines mark the transition points at $1010 \mathrm{~h}$ on Day 2 and $1810 \mathrm{~h}$ Day 2 
the stable regime, energy from the geostrophic forcing is as important as the Reynolds flux term in balancing the MKE lost due to the presence of the wind-farm with each contributing 57 and $35 \%$ respectively in the late stable period beginning $0400 \mathrm{~h}$ until $0900 \mathrm{~h}$. The relatively greater importance of the geostrophic forcing within the SBL as opposed to the CBL implies that perturbations to mesoscale flows affect wind-farm operations more strongly during nighttime stable conditions than during daytime convective conditions. The dispersive stress that is associated with the presence of wakes in the rotor-disk region is surprisingly negligible in the total rotor-disk region throughout the diurnal cycle with the exception of the unstable period.

The MKE lost due to the wind farm remains nearly constant during the stable period and increases during the unstable period to almost double the value. However the increase occurs very rapidly at $1200 \mathrm{~h}$, almost $2 \mathrm{~h}$ after the transition point at $1010 \mathrm{~h}$. We explore the reason for this delay below.

\subsection{Formation and Growth of the CBL}

Since we have imposed a similar temperature signal at the surface for both noWT and WT24 simulations, we can investigate the impact of the perturbed stress profile due to the wind farm on the formation and growth of the CBL. Here, we restate significant moments during the diurnal cycle: we denote 'sunrise' as the time when the imposed temperature at the surface (Fig. 1d) begins to rise after reaching a minimum. This occurs at $0920 \mathrm{~h}$ and is similar for both noWT and WT24 simulations. The transition to the CBL is identified as the time at which the sensible heat flux at the surface changes from negative to positive. We note that there is a 20-min difference between the noWT and the WT24 simulations, with the transition occuring at 1010 and $1030 \mathrm{~h}$ respectively.

Figure $9 \mathrm{a}-\mathrm{c}$ shows the profiles of temperature $(\theta)$, momentum flux $(\tau)$ and sensible heat flux $\left(H_{s}\right)$ respectively for the noWT simulation, while Fig. 9d, e shows the respective counterparts for the WT24 simulation. We begin our analysis $30 \mathrm{~min}$ before sunrise (at $0850 \mathrm{~h}$ ) and focus only on the early growth of the CBL.

The $0850 \mathrm{~h}$ profiles represent the quasi-steady, late stable period. In the standard flat-terrain scenario, the SBL can be considered to be a purely surface-driven phenomenon with the surface acting as a thermal sink. Mechanically-generated turbulence and associated mixing (momentum flux) due to shear at the rough wall are the only available mechanisms for extending the cooling effect (referred to as the 'cooling wave' in the literature) deeper into the atmosphere. This concept is well-described by the profiles at $0850 \mathrm{~h}$ with the cooling extending up to a height of $300 \mathrm{~m}$. At this height, the shear stress and the sensible heat flux decay to negligible values as compared to their reference surface values. The shape of the temperature profile, with the temperature gradient increasing with increasing height, provides further evidence of maximum mixing at the surface that decreases with height.

In the presence of the wind farm, turbulence and momentum flux are maximum at the top of the rotor disk rather than at the surface. In fact, as already described in Fig. 7, the integrated momentum flux in the first $50 \mathrm{~m}$ above the surface in the WT24 simulation is only $40 \%$ of that in the noWT simulation (recall that $\mathcal{L}_{\mathrm{WT} 24} / \mathcal{L}_{\text {noWT }} \approx 0.4$ ). As a consequence, the cooling effect originating at the surface is much reduced in the first $50 \mathrm{~m}$ of the WT24 simulation as compared to the noWT simulation. The profiles for the WT2 4 simulation at $0850 \mathrm{~h}$ reaffirm the lack of cooling, with the mean temperature of the first $50 \mathrm{~m}$ being $0.8 \mathrm{~K}$ higher than in the noWT simulation and a difference of $2.6 \mathrm{~K}$ at 50 -m height (i.e. the bottom of the rotor-disk region). This ultimately results in a stronger stratification beneath the rotordisk region $\left(\partial \theta /\left.\partial z\right|_{\mathrm{WT} 24}=0.1 \mathrm{~K} \mathrm{~m}^{-1}, \partial \theta /\left.\partial z\right|_{\text {noWT }}=0.03 \mathrm{~K} \mathrm{~m}^{-1}\right)$. Many previous studies 
(a)

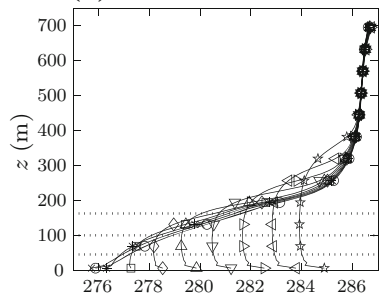

(d)

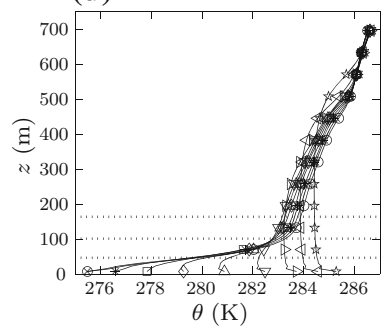

(b)

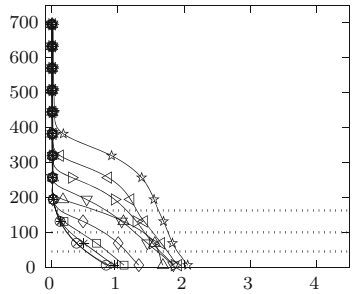

(e)

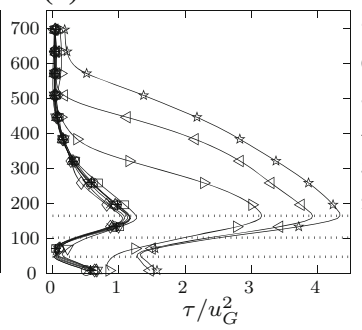

(c)

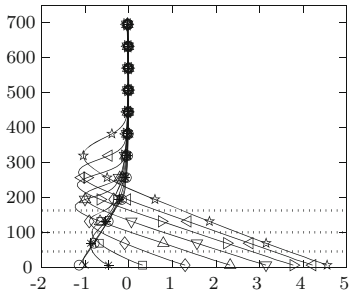

(f)

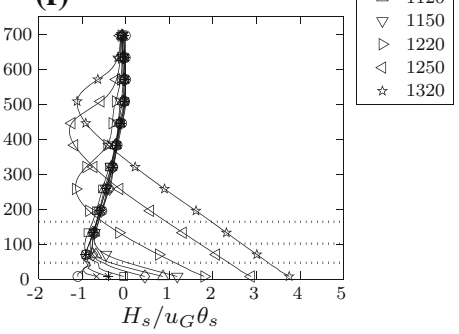

Fig. 9 Formation and growth of the CBL. Subplots a-c show the profiles of temperature, net momentum flux $\left(\times 10^{3}\right)$ and sensible heat flux $\left(\times 10^{3}\right)$ respectively for the noWT simulation. Subplots $\mathbf{d}-\mathbf{e}$ are the respective counterparts for the WT24 simulation. Each subplot contains profiles $30 \mathrm{~min}$ apart beginning at $0850 \mathrm{~h}$ on Day 2 and continuing until $1320 \mathrm{~h}$ on Day 2. Geostrophic velocity and surface temperature are used as normalization scales. The three horizontal dotted lines on each subplot mark the top, bottom and hub-height of the wind turbines

(Roy and Traiteur 2010; Lu and Porté-Agel 2011; Fitch et al. 2013a) have described a similar warming near the surface. However, for the sake of clarity, it would perhaps be more suitable to state this phenomenon as lack of cooling.

In addition, the flow above the wind farm is characterized by a negative heat flux region that extends up to a height of $500 \mathrm{~m}$ in the atmosphere, $200 \mathrm{~m}$ higher than for the noWT simulation. This is a direct consequence of the enhanced mixing available above the wind farm with the integrated momentum flux for the WT24 simulation being much larger than the noWT simulation $\left(\mathcal{H}_{\mathrm{WT} 24} / \mathcal{H}_{\text {noWT }}=20\right)$. To summarise the late SBL profile, the cooling of the ABL during stable conditions occurs differently with and without wind farms. For the WT24 simulation, there is reduced cooling between the surface and the rotor-disk region, and above the rotor-disk region, the cooling effect extends deeper into the atmosphere. Instead, in the noWT simulation, the cooling is maximum near the surface and progressively decreases with height. These differences are a direct reflection of the perturbed stress profile of the WT24 simulation.

Upon sunrise, the surface temperature rises equally in both the noWT and the WT24 simulation. The $1020 \mathrm{~h}$ profile for the noWT simulation shows a small positive sensible heat flux at the surface (transition occurs at $1010 \mathrm{~h}$ ). At $1050 \mathrm{~h}$, the initial stratification is essentially overcome with the surface temperature significantly greater than the overlying air and the shear stress begins to increase at the surface. In a matter of $30 \mathrm{~min}$, between 1050 and $1120 \mathrm{~h}$, there is an approximately $30 \%$ increase in shear at the surface and in the following period remains constant at this value while the CBL grows. The $1320 \mathrm{~h}$ profile of the momentum flux shows an interesting feature with two definite linear trends, one extending from the surface to 230 $\mathrm{m}$ and the other from thereon up to $400 \mathrm{~m}$. This corresponds identically to regions of positive sensible heat flux and the negative sensible heat flux also termed as the entrainment region. 
(a)

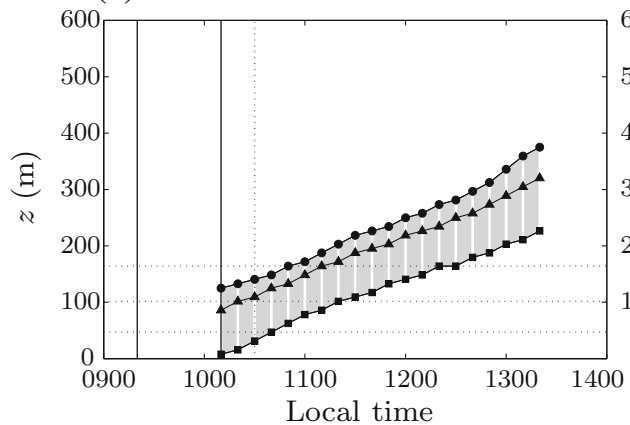

(b)

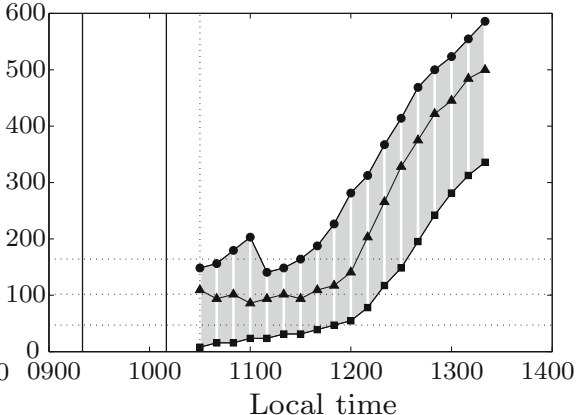

Fig. 10 Entrainment region for a the noWT simulation and b WT24 simulation. The lower edge of the shaded region (marked by square symbols) represents the height up to which the ABL is subjected to a positive $H_{S}$. The triangle symbols mark the height where the maximum value of absolute $H_{S}$ is found in the entrainment region. The upper edge of the entrainment region, marked by circular symbols is the height where the heat flux becomes zero once again. Each subplot contains 3 vertical lines, which beginning from the left represent the sunrise at $0920 \mathrm{~h}$ (solid), morning transition for noWT simulation at $1010 \mathrm{~h} \mathrm{(solid)}$ and for the WT24 simulation at $1030 \mathrm{~h}$ (dotted) respectively. The three horizontal dotted lines represent the rotor-disk region of the wind farm

On the other hand, the much stronger stratification near the surface due to the presence of the wind farm has a significant impact on the formation and growth of the CBL. At the outset, the transition event is delayed by $20 \mathrm{~min}$ as compared to the noWT simulation. Furthermore, upon transition, much of the heating is limited to below the hub-height and occurs exclusively through surface driven thermals as opposed to the noWT simulation where the heating occurs through both the surface-driven thermals and entrainment of warmer air from the residual region above. The overlying stratification is finally overcome between 1150 and $1220 \mathrm{~h}$ (almost $2.5 \mathrm{~h}$ later in comparison with the noWT simulation). During the same $30 \mathrm{~min}$, there is a remarkable $200 \%$ increase in shear stress at the top of the rotor disk. Hereafter, the CBL grows rapidly with a deeper entrainment region as evidenced by the profiles of sensible heat flux. The deeper entrainment region is a signature of the erstwhile SBL, which due to enhanced mixing induced by the wind farm extends deeper into the atmosphere.

A comparison between the entrainment region associated with the growing CBL for the noWT and WT24 simulations is made in Fig. 10a, b respectively. The entrainment region is identified from the profiles of $H_{s}$ in Fig. 9c, $\mathrm{f}$ as the region with negative $H_{S}$ (while the surface $H_{s}$ is positive) and is shaded grey. The region of the ABL between the surface and the lower edge is understood to be primarily heated by the warming surface. The upper edge of the entrainment region is difficult to identify in the late convective period, when the upper edge of the entrainment region reaches the capping inversion. The presence of the wind farms further complicates its identification as the enhanced mixing causes the sensible heat flux to decay slower vertically and to never reach zero, in certain cases up to the height of the capping inversion even in the late stable period. We used the evolution of the mean temperature gradient $(\partial\langle\bar{\theta}\rangle / \partial z)$ to identify the top of the entrainment region.

The triangular symbols mark the height at which where the maximum value of absolute $H_{S}$ is found in the entrainment region; this is also denoted as the height of the CBL used in Fig. 3. Note that the CBL grows linearly for the noWT simulation with the width of the entrainment region being nearly constant $(\approx 120 \mathrm{~m})$ throughout the growth period. On the other hand, the growth of the CBL in the WT24 simulation is perturbed and can be considered 
as following a two-stage growth: the first stage consists of the period between the transition and $1200 \mathrm{~h}$, and is characterized by two observations. Firstly, the growth of the positive $H_{S}$ region is markedly slower with respect to the noWT simulation-this is a consequence of the stronger stratification in the WT24 simulation at the end of the stable period. Secondly, the height of the CBL remains nearly fixed at hub-height and begins to rise only at $1200 \mathrm{~h}$. Onset of the second stage of CBL growth appears to be when the positive $H_{s}$ region reaches the rotor-disk region, after which the $\mathrm{CBL}$ growth is accelerated, with growth greater than the noWT simulation. It is surmised that this increase in the rate of growth is due to additional mixing in the wake region of the wind farm. Also note that the width of the entrainment region is greater in the WT24 simulation throughout the growth period (width after $1200 \mathrm{~h}$ is $\approx 250,130 \mathrm{~m}$ larger than for the noWT simulation).

We summarize the effect of wind farms on the formation and growth of the CBL as follows: as a consequence of lower mixing below the rotor-disk region causing significantly stronger stratification in the late stable period, the time lag between sunrise and transition is slightly increased $(20 \mathrm{~min})$. Upon transition, the growth of the CBL follows a two-stage process: initially, there is no growth as the stratification is overcome by the slowly growing positive $H_{s}$ region, following which the CBL grows at a rapid rate aided by additional mixing induced by the wind farms. The trigger for the onset of the second stage is the thermal plumes from the surface entering the wake region of the wind farm.

\subsection{Phenomenology of the Low-Level Jet}

Here we describe the formation of the low-level jet (LLJ) and the role of wind farms in modulating its formation. The LLJ is a loosely defined term for any maximum found in the wind profile that is shallow in the vertical but is found to extend over a wide horizontal area. LLJs are found in diverse flow scenarios such as steep and shallow sloping terrain (Shapiro and Fedorovich 2009; Oldroyd et al. 2014), the Great Plains in the United States (Whiteman et al. 1997; Banta et al. 2002) and Antarctica (Chiba and Kobayashi 1986). The LLJ is an important meteorological phenomenon that influences e.g. nocturnal scalar transport, the ventilation of urban canopies, and wind-farm operations (Stensrud 1996). Here we limit our focus to the Blackader-type nocturnal LLJ (Blackadar 1957) that forms over flat terrain at nighttime under clear-sky conditions. This type of LLJ is formed when the flow between the top of the SBL $[\mathcal{O}(100 \mathrm{~m})]$ and the overlying capping inversion $[\mathcal{O}(1000 \mathrm{~m})]$ experiences a complete decay in the momentum fluxes (see, for example, Fig. $9 \mathrm{~b}, 0850 \mathrm{~h}$ profile). In this region, the flow is essentially non-turbulent and undergoes inertial oscillations due to a lack of balance between the geostrophic and Coriolis forces (Wyngaard 2010). Within the SBL, the divergence of stress balances the geostrophic and Coriolis forcing and hence there is no time evolution in the flow. The peak of the LLJ is found at the interface between the stationary SBL layer and the overlying oscillating inviscid layer. In the noWT simulation, the jet peak occurs at $156 \mathrm{~m}$ and for the WT24 simulation it occurs at $400 \mathrm{~m}$, approximately $250 \mathrm{~m}$ higher than in the noWT simulation. This is illustrated in Fig. 11 in detail: Fig. $11 \mathrm{a}, \mathrm{c}$ shows the $\langle\bar{u}\rangle$ (closed symbols) and $\langle\bar{v}\rangle$ (open symbols) for the noWT and WT24 simulations respectively. Figure $11 \mathrm{~b}, \mathrm{~d}$ show the bulk quantities $\tau_{x}$ (closed symbols) and $\tau_{y}$ (open symbols) for the corresponding cases (see Sect. 2.2 for formulation of bulk statistics). The profiles presented span the latter half of the stable period between 0300 and $0800 \mathrm{~h}$; as in previous figures, the three horizontal regions represent the rotor-disk region.

The effect of wind farms on LLJs has been documented recently in Fitch et al. (2013a) and Abkar et al. (2016), and in both a finite-size wind farm was simulated as opposed to the infinite farm in our study. Fitch et al. (2013a) found that the LLJ developed upstream 
(a)
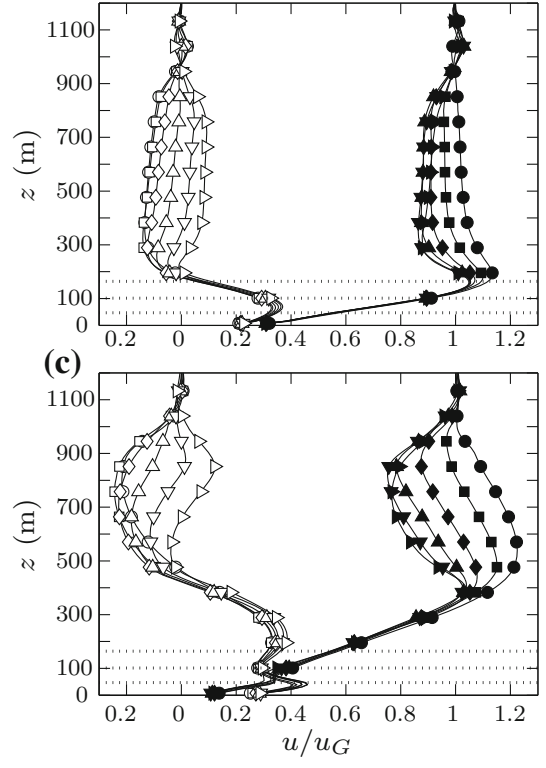

(b)

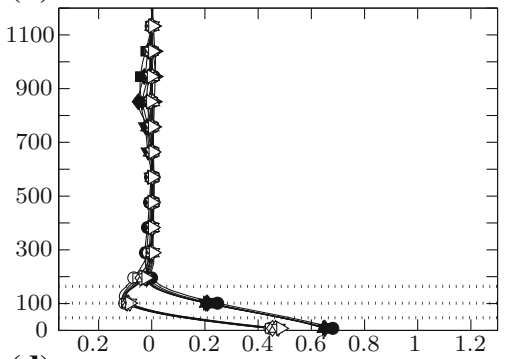

(d)

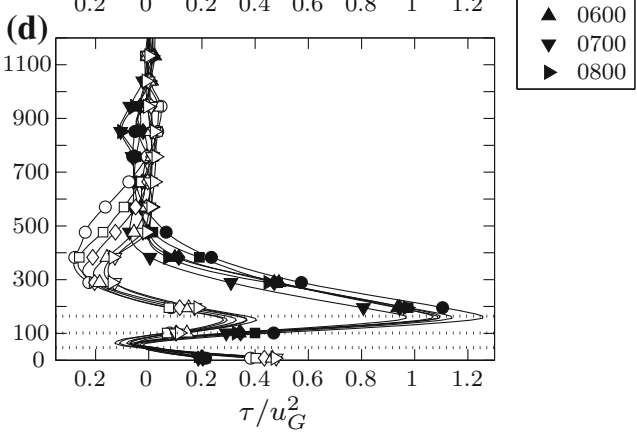

Fig. 11 Formation of the LLJ: subplots a and $\mathbf{c}$ show the $\langle\bar{u}\rangle$ (closed symbols) and $\langle\bar{v}\rangle$ (open symbols) for the noWT and WT24 simulations respectively. Subplots $\mathbf{b}$ and $\mathbf{d}$ show the bulk quantities $\tau_{x}$ (closed symbols) and $\tau_{y}$ (open symbols) for the corresponding cases (see Sect. 2.2 for formulation of bulk statistics). The profiles presented span the latter half of the stable period between 0300 and $0800 \mathrm{~h}$ on Day 2. The three horizontal lines represent the rotor-disk region. All values are normalized using geostrophic velocity. The stress values are scaled by a factor of $10^{-3}$

of the wind farm, and is depleted by the first two rows. In fact, they showed that, due to the effect of the LLJ, the upstream wind turbines generate much more power at night as compared to the wind turbines deep within the wind farm. A similar scenario was also observed by Abkar et al. (2016), who additionally showed that the LLJ was shifted upwards and is re-generated above the wind farm; much like the present results. To reconcile our infinite wind-farm results with these works, a solitary wind turbine was placed in the diurnal $\mathrm{ABL}$ simulation. Due to the effect of the periodic boundary conditions, this in effect simulates an infinite wind farm with extremely large spacing. This simulation is denoted as WT1 with $s_{x}, s_{y}=1000 \pi \mathrm{m}=31.5 D$, in comparison to $s_{x}=7 D, s_{y}=5 D$ for the WT2 4 simulation and $s_{x}, s_{y}=1000 \mathrm{~m}=10 D$ for the Fitch et al. (2013a) case.

Figure 12 shows an illustration of the WT1 simulation during the LLJ event; from the 10min averaged velocity field, a vertical slice passing through the centre of the wind turbine is extracted. It can be clearly seen that the LLJ affects the wind turbine and persists continuously downstream of the wind turbine as well. In fact, the mean field is perturbed quasi-linearly as the wake is simply superimposed on the mean field. An implication of this fact is shown in Fig. 13 where the mean 10-min averaged power of a wind turbine in the WT24 simulation (blue line) is compared with the single wind turbine in the WT1 simulation (black line) during the course of the diurnal cycle. The power $P$ computed as $P=\sum r F_{r} \omega$, where $F_{r}$ is the tangential force at a point at distance $r$ from the centre of the rotor disk, $\omega$ is the angular velocity of the wind turbine and the summation represents integration over the entire rotor disk (see Sharma et al. 2015, for a detailed description of the wind-turbine parametrization). Note 


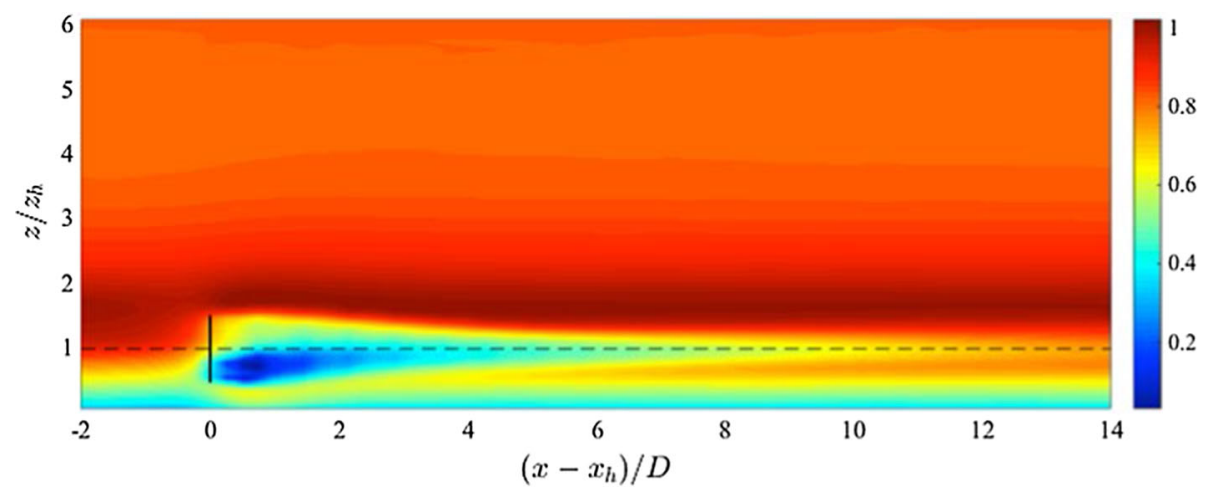

Fig. 12 Illustration of the LLJ impact upon the wind turbine in the WT1 simulation. A vertical slice passing through the rotor disk of the 10 -min averaged normalized velocity magnitude field. The horizontal and vertical axes are scaled using the rotor diameter $(D)$ and the hub-height $\left(z_{h}\right)$, respectively

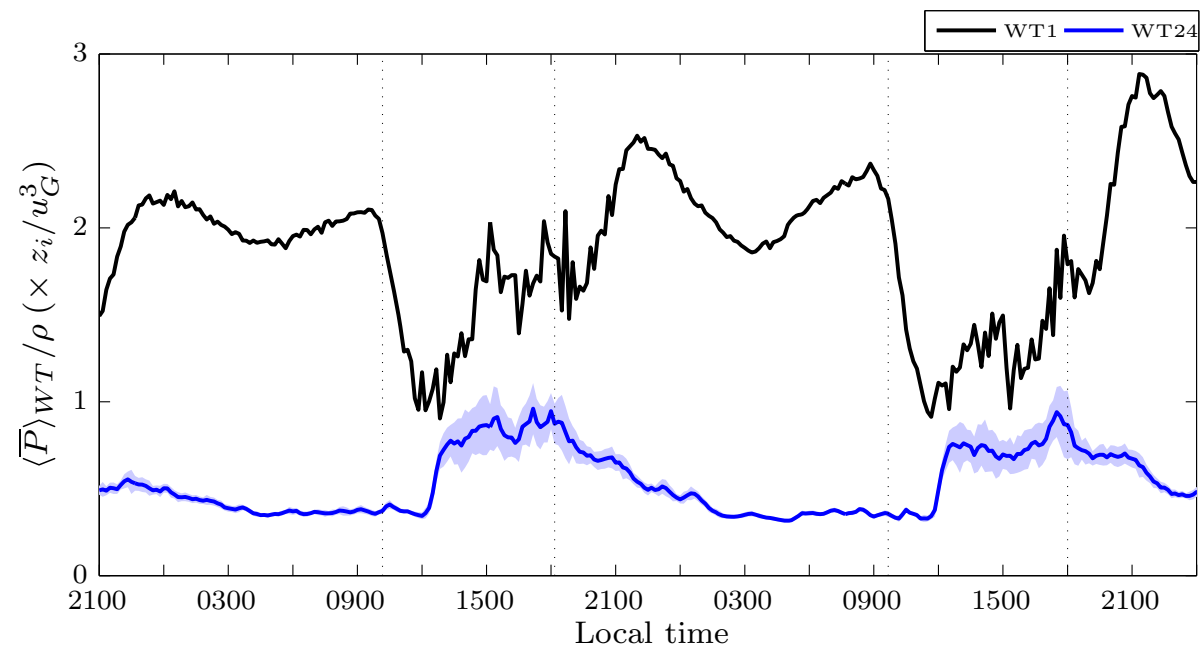

Fig. 13 Temporal evolution of the normalized available power for extraction at the wind-turbine rotor disk. The single black line represents the WT1 simulation and the blue line represents the mean for the WT24 simulation; the shaded blue region illustrates the standard deviation for the WT24 simulation. The power values are scaled by a factor of $10^{3}$, while the vertical lines represent the transition points. The four vertical lines mark the transition points at 1010 and $1810 \mathrm{~h}$ on Day 2 and 0940 and $1800 \mathrm{~h}$ on Day 3

that in the WT1 simulation, due to extremely low loading of the surface, the wind speeds are higher and as a consequence, so is the power output. However, the more interesting observation is that in the WT1 simulation, the stable period has a greater $(\approx 40 \%$ more) power output in comparison to the unstable period, whereas in the WT24 simulation this trend is opposite, with the power output being twice as large as that during the stable period. This is a direct result of the fact that, at nighttime, the WT1 simulation is able to extract power from the LLJ while in the WT24 simulation, the LLJ forms above the rotor-disk region. The comparison between WT1 and WT24 simulations, in addition to the results presented in Fitch et al. (2013a) and Abkar and Porté-Agel (2015a), hints towards a high dependence of wind-farm power output on loading during stably stratified conditions. 


\subsection{Effective Roughness Lengths of a Wind Farm During a Diurnally-Varying ABL}

Over the past few years different formulations have been proposed for a wind-farm-induced surface roughness under neutral stratification (Frandsen 1992; Calaf et al. 2010; Stevens et al. 2014). Some of these formulations have been used in climate studies (Keith et al. 2004; KirkDavidoff and Keith 2008; Barrie and Kirk-Davidoff 2010; Wang and Prinn 2010) to study the potential impact of large-scale wind-energy deployment on the global atmospheric circulation. More recently, improved parametrizations accounting for the effect of atmospheric stratification have also been developed (Peña and Rathmann 2014; Sescu and Meneveau 2015). In this section we further explore the induced change on the wind-farm induced surface roughness due to the time-varying atmospheric stratification typically found in a diurnal cycle. Our aim is to highlight the possible pitfall of using the wind-farm-induced surface roughness values computed in GCMs assuming neutral stratification.

For the standard flat-terrain $\mathrm{ABL}$, the mean velocity profile in the surface layer for stratified conditions can be expressed as

$$
\frac{\langle\bar{u}\rangle(z)}{u_{\star}}=\frac{1}{\kappa}\left[\ln \left(\frac{z}{z_{0}}\right)+\beta\right]
$$

where $\beta$ is a stability correction function (with $\beta=0$ signifying neutral conditions), and $z_{0}$ is the aerodynamic roughness length. Upon manipulation of the above equation, it is possible to obtain an expression for an equivalent effective roughness length that includes the effect of atmospheric stratification, $z_{0, \text { eff }}$, such as

$$
z_{0, \text { eff }}=z_{0} e^{-\beta}=z \exp \left[-\langle\bar{u}\rangle_{\kappa} / u_{\star}\right]
$$

Note that for the case of $\beta=0$, the equation recovers the expected value for the neutral case, $z_{0, \text { eff }}=z_{0}$. This approach of including the effect of stratification in the surface roughness formulation can be further expanded to the case where a large wind farm is present. Therefore the counterpart of Eq. 4 for flow over a wind farm can be written as,

$$
\begin{aligned}
\frac{\langle\bar{u}\rangle(z)}{u_{\star, \mathrm{wf}}} & =\frac{1}{\kappa}\left[\ln \left(\frac{z}{z_{\mathrm{wf}}}\right)+\beta^{\mathrm{wf}}\right] \\
& =\frac{1}{\kappa}\left[\ln \left(\frac{z}{z_{\mathrm{wf}} e^{-\beta_{\mathrm{wf}}}}\right)\right] \\
& =\frac{1}{\kappa}\left[\ln \left(\frac{z}{z_{\mathrm{wf}, \mathrm{eff}}}\right)\right],
\end{aligned}
$$

for $z \geq z_{h}+D / 2$, where $\beta^{\text {wf }}$ is an equivalent stability correction function for the wind farm and $z_{\mathrm{wf} \text {,eff }}$ represents the effective wind-farm roughness for stratified conditions. Again, upon manipulation it is possible to obtain an expression for $z_{\mathrm{wf}, \text { eff }}$ as follows,

$$
z_{\mathrm{wf}, \mathrm{eff}}=z \exp \left[\langle\bar{u}\rangle \kappa / u_{\star, \mathrm{wf}}\right],
$$

for $z \geq z_{h}+D / 2$. Equations 5 and 7 are used to compute the corresponding values of effective roughness using LES model data. The effective roughness calculation requires a choice of height at which reference velocity values are extracted. In the present case, the heights of 3.9 $\mathrm{m}$ (the first grid point above the surface) and $200 \mathrm{~m}\left(2 z_{h}\right)$ are chosen for the noWT and the WT24 simulations respectively. Note that this is an unusual way to formulate the modified surface roughness because it directly includes the effect of atmospheric stability, and hence becomes height dependent. However, because the stability correction functions used become 


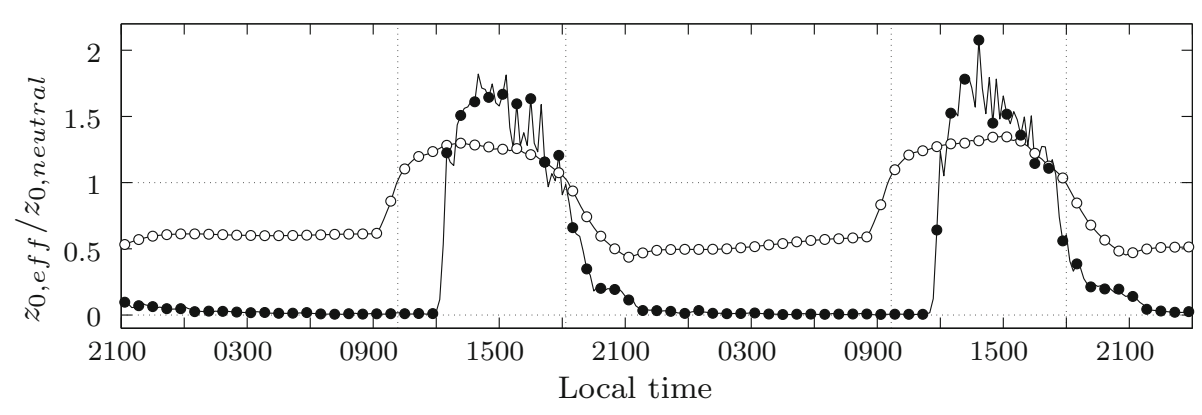

Fig. 14 Temporal evolution of the effective roughness for the noWT simulation ( $z_{0}$, eff, open markers) and the WT24 simulation ( $\left.z_{\mathrm{wf}, \text { eff }}\right)$, closed markers. Values are normalized by the corresponding roughness lengths for neutral conditions $\left(z_{0}\right.$ and $\left.z_{\mathrm{wf}}\right)$. The four vertical lines mark the transition points at 1010 and $1810 \mathrm{~h}$ on Day 2 and 0940 and 1800 h on Day 3

constant with height from $|z / L|>2$ to 3 ( $L \approx 40 \mathrm{~m}$ height in the presented diurnal cycle), the actual value of the wind-farm-induced surface roughness remains effectively heightindependent. Additional calculations using data from different heights have been performed and results (not shown here) confirm this fact. The vertical momentum-flux values were taken at the surface and the top of the rotor-disk region for noWT and WT24 simulations respectively. The computed effective roughness values are normalized by the respective neutral $z_{0}$ values of (for the noWT simulation, imposed as $0.03 \mathrm{~m}$ ) and $z_{\mathrm{wf}}$ (computed for the WT24 simulation to be equal to $2.4 \mathrm{~m}$ ) and are shown in Fig. 14. The corresponding wind-farm surface roughness for neutral conditions $\left(z_{\mathrm{wf}}\right)$ has been obtained using Calaf et al. (2010)'s expression based on the geometry of the wind farm (streamwise and spanwise spacing), therein referred as $z_{0, h i}$. Note that this normalization helps identify the deviations in the modified surface roughness (Eqs. 5 and 7) from the neutrally stratified conditions, with values $>1$ signifying 'high roughness' unstable conditions and $<1$ signifying 'low roughness' stable conditions.

As expected, the normalized effective roughness $=1$ for the noWT simulation at the transition points (marked by four vertical dotted lines). The results for the WT24 simulation are far more surprising, where the effect of the delayed formation and growth of the CBL is seen as the effective roughness increases to values $>1$ at $1200 \mathrm{~h}, 2 \mathrm{~h}$ after the transition. The transition from unstable to stable conditions on the other hand occurs approximately at the same time. However, during the stable period, the effective roughness decreases by several orders of magnitude; the average effective roughness $\left(\overline{z_{0, \text { eff }}}\right)$ during a 24 -h period beginning at $0000 \mathrm{~h}$ on Day 2 for the noWT simulation was computed as $0.024 \mathrm{~m}\left(80 \%\right.$ of $\left.z_{0}\right)$ whereas for the WT24 simulation, $\overline{z_{\mathrm{wf}, \mathrm{eff}}}$, it was found to be equal to $0.96 \mathrm{~m}$ (40\% of $z_{\mathrm{wf}}$ ). The extended stable period during the simulation as imposed by the adopted temperature signal at the surface is represented well by the fact that, in both the noWT and WT24 simulations, the effective roughness values are found to be smaller than the reference value for neutral stratification. However, the decrease in the WT24 simulation values is markedly larger. This result is pertinent to the use of enhanced surface roughness representation for terrestrial wind farms in GCM simulations, and illustrates the need for using a surface roughness parametrization that not only includes the effect of wind farms but also the time-varying atmospheric stratification. 


\section{Summary and Conclusions}

We studied the impact of an extremely large wind farm on the spatio-temporal structure of a diurnally-varying ABL. Towards this end, computational experiments using LES were performed for cases with and without wind turbines (denoted as WT24 and noWT respectively) during a diurnal cycle forced with data from the CASES-99 field campaign. The noWT simulation was used for validating the computational set-up through comparison with the existing literature. In addition, it served as the baseline case to delineate the perturbations induced by wind farms.

The WT24 simulation reaffirmed previous results, namely, the formation of the LLJ above the wind farm, depletion of turbulence and mixing beneath the rotor-disk region and deeper and stronger entrainment region in the quasi-steady CBL in the presence of wind farms in comparison to the noWT simulation.

New insights and their implications for the wind-energy community are summarized as follows. The MKE budget revealed the important role played by large-scale forcing (the geostrophic flow in our case) for wind-farm operations during stably stratified conditions as opposed to convective conditions where their effect was less significant. This implies that wind-farm operators need to be mindful of perturbations in the mesoscale flow during nighttime operations. Further, the daytime (unstable conditions) power output was found to be almost twice as large as that at nighttime (stable conditions).

Operating the wind farm during the stably stratified period produced two major perturbations, firstly, the LLJ was shifted upwards and the wind farm was unable to benefit from the high wind speeds found in the LLJ peak (this resulted in lower power output at night). Secondly, the operation of the wind farm caused a stronger stratification beneath the rotordisk region and consequently, a significant timelag was found $(2 \mathrm{~h})$ for the formation and growth of the CBL. This phenomenon results in a delay in achieving the higher power output available during daytime. On the other hand, through an ancillary simulation with very low loading (WT1), we found that these perturbations can be mitigated, particularly with respect to the LLJ. Thus, it may be advantageous for wind-farm operators to optimize their operation and maintenance schedules by lowering the wind-farm loading at nighttime. This would result in the wind farm being able to extract kinetic energy from the inertial oscillations and the LLJ that would now occur at a lower height. Secondly, a weaker stratification allows the CBL to grow more rapidly upon transition and significantly reduce the timelag between low-power nighttime conditions and high-power daytime conditions. Later, the loading of the wind farm could be increased as soon as the CBL top reaches the rotor-disk region. An additional perturbation induced by large wind farms is the increase in the vertical extent of the entrainment region (108\% increase) capping the CBL along with stronger entrainment fluxes (78\% increase).

The final contribution has been to show that the diurnally-averaged wind-farm effective roughness is significantly lower (40\% in our case) than the effective roughness computed for neutral conditions. Specifically, $z_{\mathrm{wf}}$,eff ranges between a low value of $0.04 \mathrm{~m}$ (found during the stable stratification) and $3.6 \mathrm{~m}$ (during the unstable conditions). Therefore, care should be taken when using an effective surface roughness parametrization within GCMs to study the impact of large-scale wind-farm deployment on climate dynamics. The theoretical formulation for effective roughness during neutral conditions as representative of the diurnally-averaged value may be inappropriate.

Acknowledgements The authors would like to thank Dr. Oldroyd for reading the manuscript and providing valuable comments. The work was made possible by support received through the Swiss National Science 
Foundation (Project No. 200021134892/1 and 20020 125092), ETH Domain Centre for Competence in Environmental Sustainability, NSERC Discovery Grant (MBP), Swiss National Supercomputing Center (CSCS), Scientific IT and Application Support (SCITAS) group at EPFL, University of Utah and University of British Columbia.

\section{References}

Abkar M, Porté-Agel F (2013) The effect of free-atmosphere stratification on boundary-layer flow and power output from very large wind farms. Energies 6:2338-2361. doi:10.3390/en6052338

Abkar M, Porté-Agel F (2015a) Influence of atmospheric stability on wind-turbine wakes: a large-eddy simulation study. Phys Fluids 27(035104):1-19. doi:10.1063/1.4913695

Abkar M, Porté-Agel F (2015b) A new wind-farm parameterization for large-scale atmospheric models. J Renew Sustain Energy 7(1):013,121

Abkar M, Sharifi A, Porté-Agel F (2016) Wake flow in a wind farm during a diurnal cycle. J Turbul 17(4):420441

Aitken ML, Kosović B, Mirocha JD, Lundquist JK (2014) Large eddy simulation of wind turbine wake dynamics in the stable boundary layer using the weather research and forecasting model. J Renew Sustain Energy 6(3):033,137

Albertson JD, Parlange MB (1999a) Natural integration of scalar fluxes from complex terrain. Water Resour Res 23:239-252

Albertson JD, Parlange MB (1999b) Surface length-scales and shear stress: implications for land-atmosphere interaction over complex terrain. Water Resour Res 35:2121-2131

Baker RW, Walker SN (1984) Wake measurements behind a large horizontal axis wind turbine generator. Sol Energy 33(1):5-12. doi:10.1016/0038-092X(84)90110-5

Banta R, Newsom R, Lundquist J, Pichugina Y, Coulter R, Mahrt L (2002) Nocturnal low-level jet characteristics over kansas during cases-99. Boundary-Layer Meteorol 105(2):221-252

Barrie D, Kirk-Davidoff D (2010) Weather response to a large wind turbine array. Atmos Chem Phys 10(2):769775

Barthelemie RJ, Jensen L (2010) Evaluation of wind farm efficiency and wind turbine wakes at the Nysted offshore wind farm. Wind Energy 13:573-586

Barthelmie RJ, Rathmann O, Frandsen ST, Hansen KS, Politis E, Prospathopoulos J, Rados K, Cabezón D, Schlez W, Phillips J, Neubert a, Schepers JG, Pijl SPVD (2007) Modelling and measurements of wakes in large wind farms. J Phys Conf Ser 75(012):049. doi:10.1088/1742-6596/75/1/012049

Barthelmie RJ, Hansen K, Frandsen ST, Rathmann O, Schepers JG, Schlez W, Phillips J, Rados K, Zervos a, Politis ES, Chaviaropoulos PK (2009) Modelling and measuring flow and wind turbine wakes in large wind farms offshore. Wind Energy 12(June):431-444. doi:10.1002/we.348

Barthelmie RJ, Pryor SC, Frandsen ST, Hansen KS, Schepers JG, Rados K, Schlez W, Neubert a, Jensen LE, Neckelmann S (2010) Quantifying the impact of wind turbine wakes on power output at offshore wind farms. J Atmos Ocean Technol 27(8):1302-1317. doi:10.1175/2010JTECHA1398.1

Basu S, Vinuesa JF, Swift A (2008) Dynamic LES modeling of a diurnal cycle. J Appl Meteorol Clim 47(4):1156-1174

Bhaganagar K, Debnath M (2015) The effects of mean atmospheric forcings of the stable atmospheric boundary layer on wind turbine wake. J Renew Sustain Energy 7(1):013124

Blackadar AK (1957) Boundary layer wind maxima and their significance for the growth of nocturnal inversions. Bull Am Meteorol Soc 38(5):283-290

Bou-Zeid E, Meneveau C, Parlange MB (2005) A scale-dependent Lagrangian dynamic model for large-eddy simulation of complex turbulent flows. Phys Fluids 17:1-18

Brutsaert W (1992) Stability correction functions for the mean wind speed and temperature in the unstable surface layer. Geophys Res Lett 19(5):469-472. doi:10.1029/92GL00084

Brutsaert W, Gash J, Parlange MB (1989) Neutral humidity profiles in the boundary layer and regional evaporation from sparse pine forest. Ann Geophys 7:623-630

Cal RB, Lebrón J, Castillo L, Kang HS, Meneveau C (2010) Experimental study of the horizontally averaged flow structure in a model wind-turbine array boundary layer. J Renew Sustain Energy 2(1):013,106

Calaf M, Meyers J, Meneveau C (2010) Large eddy simulation study of fully developed wind-turbine array boundary layers. Phys Fluids 22(015110):1-16

Calaf M, Parlange MB, Meneveau C (2011) Large eddy simulation of scalar transport in fully developed wind-turbine array boundary layers. Phys Fluids 23(126603):1-16 
Calaf M, Higgins C, Parlange MB (2014) Large wind farms and the scalar flux over an heterogeneously rough land surface. Boundary-Layer Meteorol 153(3):471-495

Canuto C, Hussaini MY, Quarteroni A, Zang TA (1988) Fundamentals of spectral methods for PDEs. In: Spectral methods in fluid dynamics, Chap 3. Springer, Berlin, pp 76-93

Chiba O, Kobayashi S (1986) A study of the structure of low-level katabatic winds at Mizuho Station, east Antarctica. Boundary-Layer Meteorol 37(4):343-355

Churchfield MJ, Lee S, Michalakes J, Moriarty PJ (2012) A numerical study of the effects of atmospheric and wake turbulence on wind turbine dynamics. J Turbul 13(February 2015):N14. doi:10.1080/14685248. 2012.668191

Derbyshire SH (1990) Nieuwstadt's stable boundary layer revisited. Q J R Meteorol Soc 116(491):127-158

Emeis S, Frandsen S (1993) Reduction of horizontal wind speed in a boundary layer with obstacles. BoundaryLayer Meteorol 64(1980):297-305. doi:10.1007/BF00708968

Finnigan J (2000) Turbulence in plant canopies. Annu Rev Fluid Mech 32(1):519-571

Fitch AC, Olson JB, Lundquist JK, Dudhia J, Gupta AK, Michalakes J, Barstad I (2012) Local and mesoscale impacts of wind farms as parameterized in a mesoscale NWP model. Mon Weather Rev 140(9):30173038

Fitch AC, Lundquist JK, Olson JB (2013a) Mesoscale influences of wind farms throughout a diurnal cycle. Mon Weather Rev 141(7):2173-2198

Fitch AC, Olson JB, Lundquist JK, Dudhia J, Gupta AK, Michalakes J, Barstad I (2013b) Local and mesoscale impacts of wind farms as parametrized in a mesoscale NWP model. Mon Weather Rev 140:3017-3038

Frandsen S (1992) On the wind speed reduction in the center of large clusters of wind turbines. J Wind Eng Ind Aerodyn 39:251-265

Frandsen S, Barthelmie R, Pryor S, Rathmann O, Sr Larsen, Højstrup J, Thøgersen M (2006) Analytical modelling of wind speed deficit in large offshore wind farms. Wind Energy 9:39-53. doi:10.1002/we. 189

Frigo M, Johnson S (2005) The design and implementation of FFTW3. Proc IEEE 93(2):216-231

Giometto MG, Christen A, Meneveau C, Fang J, Krafczyk M, Parlange MB (2016) Spatial characteristics of roughness sublayer mean flow and turbulence over a realistic urban surface. Boundary-Layer Meteorol 1-28. doi:10.1007/s10546-016-0157-6

Hancock P, Pascheke F (2010) Wind tunnel simulations of wind turbine wake interactions in neutral and stratified wind flow. In: 10th EMS annual meeting, 10th European conference on applications of meteorology (ECAM)

Higgins C, Vache K, Calaf M, Hassanpour E, Parlange MB (2015) Wind turbines and water in irrigated areas. Agric Water Manag 152:299-300. doi:10.1016/j.agwat.2014.11.016. http://linkinghub.elsevier. com/retrieve/pii/S0378377414003771

Hultmark M, Calaf M, Parlange MB (2013) A new wall shear stress model for atmsopheric boundary layer. J Atmos Sci 70:3460-3470

Iungo GV, Porté-Agel F (2014) Volumetric LiDAR scanning of wind turbine wakes under convective and neutral atmospheric stability regimes. J Atmos Ocean Technol 31(10):2035-2048. doi:10.1175/JTECHD-13-00252.1

Jensen N (1983) A note on wind generator interaction. Risø-M No. 2411, pp 1-16

Katic I, Højstrup J, Jensen NO (1986) A simple model for cluster efficiency. In: European Wind Energy Association conference and exhibition, pp 407-410

Keck RE, Maré M, Churchfield MJ, Lee S, Larsen G, Madsen HA (2014) On atmsopheric stability in the dynamic wake meandering model. Wind Energy 17:1689-1710

Keith D, DeCarolis J, Denkenberger D, Lenschow D, Malyshev S, Pacala S, Rasch P (2004) The influence of large-scale wind power on global climate. Proc Natl Acad Sci USA 101(46):16,115-16,120

Kirk-Davidoff DB, Keith DW (2008) On the climate impact of surface roughness anomalies. J Atmos Sci 65:2215-2234

Kumar V, Svensson G, Holtslag A, Meneveau C, Parlange MB (2010) Impact of surface flux formulations and geostrophic forcing on large-eddy simulations of diurnal atmospheric boundary layer flow. J Appl Meteorol Clim 49(7):1496-1516

Lissaman PBS (1979) Energy effectiveness of arbitrary arrays of wind turbines. J Energy 3(6):323-328

Lu H, Porté-Agel F (2011) Large-eddy simulation of a very large wind farm in a stable atmospheric boundary layer. Phys Fluids 23(065101):1-19

Lu H, Porté-Agel F (2015) On the impact of wind farms on a convective atmospheric boundary layer. BoundaryLayer Meteorol 157(1):81-96

Magnusson M, Smedman AS (1994) Influence of atmospheric stability on wind-turbine wakes. Wind Energy 18:139-152

Mahrt L, Lenschow D (1976) Growth dynamics of the convectively mixed layer. J Atmos Sci 33(1):41-51 
Markfort CD, Zhang W, Porté-Agel F (2012) Turbulent flow and scalar transport through and over aligned and staggered wind farms. J Turbul 13(1):N33

Meneveau C (2012) The top-down model of wind farm boundary layers and its applications. J Turbul 13:N7. doi:10.1080/14685248.2012.663092

Meyers J, Meneveau C (2010) Large eddy simulations of large wind-turbine arrays in the atmospheric boundary layer. In: 48th AIAA aerospace sciences meeting including the new horizons forum and aerospace exposition

Moeng CH (1984) A large-eddy simulation model for the study of planetary boundary-layer turbulence. J Amtos Sci 41:2052-2062

Monin A, Obukhov A (1954) Basic laws of turbulent mixing in the ground layer of the atmsophere. Tr Geofiz Int Akad Nauk SSSR 151:163-187

Nieuwstadt F, Brost R (1986) The decay of convective turbulence. J Atmos Sci 43(6):532-546

Oldroyd HJ, Katul G, Pardyjak ER, Parlange MB (2014) Momentum balance of katabatic flow on steep slopes covered with short vegetation. Geophys Res Lett 41(13):4761-4768

Peña A, Rathmann O (2014) Atmospheric stability-dependent infinite wind-farm models and the wake-decay coefficient. Wind Energy 17(8):1269-1285

Porté-Agel F, Wu YT, Chen CH (2013) A numerical study of the effects of wind direction on turbine wakes and power losses in a large wind farm. Energies 6(10):5297-5313. doi:10.3390/en6105297

Poulos GS, Blumen W, Fritts DC, Lundquist JK, Sun J, Burns SP, Nappo C, Banta R, Newsom R, Cuxart J et al (2002) Cases-99: a comprehensive investigation of the stable nocturnal boundary layer. Bull Am Meteorol Soc 83(4):555-581

Povitsky A, Morris PJ (2000) A higher-order compact method in space and time based on parallel implementation of the Thomas algorithm. J Comput Phys 161(1):182-203

Roy SB (2011) Simulating impacts of wind farms on local hydrometeorology. J Wind Eng Ind Aerodyn 99:491-498

Roy SB, Traiteur JJ (2010) Impacts of wind farms on surface air temperatures. Proc Natl Acad Sci USA 107(42):17,899-17,904

Sescu A, Meneveau C (2015) Large-eddy simulation and single-column modeling of thermally stratified wind turbine arrays for fully developed, stationary atmospheric conditions. J Atmos Ocean Technol 32(6):1144-1162

Shapiro A, Fedorovich E (2009) Nocturnal low-level jet over a shallow slope. Acta Geophys 57(4):950-980

Sharma V, Calaf M, Lehning M, Parlange MB (2015) An LES model for a time-adaptive wind turbine. Wind Energy. doi:10.1002/we.1877

Shin HH, Hong SY (2011) Intercomparison of planetary boundary-layer parametrizations in the WRF model for a single day from CASES-99. Boundary-Layer Meteorol 139(2):261-281

Sorbjan Z (1997) Decay of convective turbulence revisited. Boundary-Layer Meteorol 82(3):503-517

Stensrud DJ (1996) Importance of low-level jets to climate: a review. J Clim 9(8):1698-1711

Stevens RJAM, Gayme DF, Meneveau C (2014) Large eddy simulation studies of the effects of alignment and wind farm length. J Renew Sustain Energy 6(2):023105

Sun WY, Ogura Y (1980) Modeling the evolution of the convective planetary boundary layer. J Atmos Sci 37(7):1558-1572

Svensson G, Holtslag A, Kumar V, Mauritsen T, Steeneveld G, Angevine W, Bazile E, Beljaars A, de Bruijn E, Cheng A, Conangla L, Cuxart J, Ek M, Falk MJ, Freedman F, Kitagawa H, Larson VE, Lock A, Mailhot J, Masson V, Park S, Pleim J, Söderberg S, Weng W, Zampieri M (2011) Evaluation of the diurnal cycle in the atmospheric boundary layer over land as represented by a variety of single-column models: the second GABLS experiment. Boundary-Layer Meteorol 140(2):177-206

Tseng YH, Meneveau C, Parlange MB (2006) Modeling flow around bluff bodies and predicting urban dispersion using large eddy simulation. Environ Sci Technol 40(8):2653-2662

Wang C, Prinn RG (2010) Potential climatic impacts and reliability of very large-scale wind farms. Atmos Chem Phys 10(4):2053-2061

Whiteman CD, Bian X, Zhong S (1997) Low-level jet climatology from enhanced rawinsonde observations at a site in the southern great plains. J Appl Meteorol 36(10):1363-1376

Wu YT, Porté-Agel F (2011) Large-eddy simulation of wind-turbine wakes: evaluation of turbine parametrizations. Boundary-Layer Meteorol 138:345-366. doi:10.1007/s10546-010-9569-X

Wyngaard JC (2010) Turbulence in the atmosphere. Cambridge University Press, Cambridge, 406 pp

Wyngaard JC, Coté O (1974) The evolution of a convective planetary boundary layer-a higher-order-closure model study. Boundary-Layer Meteorol 7(3):289-308

Xia G, Zhou L, Freedman JM, Roy SB, Harris RA, Cervarich MC (2015) A case study of effects of atmospheric boundary layer turbulence, wind speed, and stability on wind farm induced temperature changes using observations from a field campaign. Clim Dyn 46(7):2179-2196 
Zhang W, Markfort CD, Porté-Agel F (2013) Experimental study of the impact of large-scale wind farms on land-atmosphere exchanges. Environ Res Lett 8(015002):1-8. doi:10.1088/1748-9326/8/1/015002

Zhou L, Tian Y, Roy SB, Thorncroft C, Bosart LF, Hu Y (2012) Impacts of wind farms on land surface temperature. Nature Clim Change 2(7):539-543 